\title{
Article
}

\section{Students' Perceptions of Doctoral Defense Formats}

\author{
Eva O. L. Lantsoght 1,2 (D) \\ 1 Department of Engineering Structures, Delft University of Technology, 2628 CN Delft, The Netherlands; \\ e.o.l.lantsoght@tudelft.nl \\ 2 Politécnico, Universidad San Francisco de Quito, Quito 170157 EC, Ecuador
}

check for

updates

Citation: Lantsoght, E.O.L. Students Perceptions of Doctoral Defense Formats. Educ. Sci. 2021, 11, 519. https://doi.org/10.3390/ educsci11090519

Academic Editor: Eleanor Dommett

Received: 1 July 2021

Accepted: 2 September 2021

Published: 8 September 2021

Publisher's Note: MDPI stays neutral with regard to jurisdictional claims in published maps and institutional affiliations.

Copyright: (C) 2021 by the author. Licensee MDPI, Basel, Switzerland. This article is an open access article distributed under the terms and conditions of the Creative Commons Attribution (CC BY) license (https:// creativecommons.org/licenses/by/ $4.0 /)$.

\begin{abstract}
The doctoral defense is an important step in the doctoral journey and an essential requirement for obtaining a doctoral degree. Past research on the doctoral defense has focused solely on national practices. In this work, I investigate the potential link between the doctoral defense format based on its major and minor elements and the perception of the defense by the student. For this purpose, I first reviewed the different defense formats used internationally to extract the different elements of the doctoral defense, and the literature on students' perceptions of the doctoral defense. Then, I carried out an international survey which received 297 responses, of which 204 were completed surveys which I used for the analysis in this article. I first analyzed the outcomes of the survey using qualitative and quantitative methods, and then cross-correlated the outcomes of defense format with the outcomes of student perception. From this analysis, I observed that the defense elements that positively impact the student's perception are: publication of the thesis before the defense, receiving committee feedback before the defense, knowing the recommendations of one or more committee member in advance, having the supervisor present in the audience or as part of the committee, using a dress code, and including a laudatio. The final conclusion of this work is threefold. The first conclusion is that the details of the defense format impact most the students' perception. The second conclusion is that doctoral students, on average, value the defense as a positive experience. The third conclusion is that the defense format cannot influence two important aspects of how a student perceives the defense: the student's inner life and experience during the defense, and the behavior of the committee members.
\end{abstract}

Keywords: assessment; best practices; defense formats; doctoral defense; doctoral students; PhD thesis; quantitative research; student perception; viva; viva voce

\section{Introduction}

The PhD defense is considered a part of the PhD examination process and a requirement for obtaining a doctoral degree [1]. Since the defense is a form of an oral exam, and crucial for obtaining a doctoral degree, it is important for candidates and committee members to understand the requirements. This preparation is important so that students can know what to expect during the doctoral defense, as this knowledge will help them prepare properly for the defense [2]. In terms of what students want from their defense, Wellington [3] observed that they want a "quality experience": a challenging experience that allows for deep discussion with experts in the field, and a process that allows feedback and the opportunity to improve. Other terms that are used for the defense are viva voce or viva (in the UK), disputation (in Sweden [4]), and disputas (in Norway [4]). The committee members also play an important role in the defense. Other terms that are sometimes used for the committee members are examiners (in the UK), and opponents (in Sweden and Norway [4]). For consistency, I solely use the terms "defense" and "committee member(s)" in this paper, even when referring to defenses from regions and countries where different terms are used.

The requirements for the $\mathrm{PhD}$ defense tend to be largely consistent among universities that use the same defense format. Even though there is a multitude of defense formats, 
"Students across all disciplines can expect to defend their thesis through a process involving questioning, clarification and discussion of key elements" [2]. An analysis of the guidelines from 20 British universities showed that the key criteria are the same [5], but that at the same time there are also differences in procedures and practices across universities. Key criteria for receiving the doctoral degree included providing an original contribution to knowledge [6], being able to locate the research in the broader context, and displaying knowledge of the contents of the written thesis. At the same time, it is not always clear whether [2] it is the thesis (as a complete and comprehensive document) or the student (as an apprentice researcher) that is being examined during the defense. In addition, some differences are discernible across disciplines. As such, getting ready for one's defense has been compared to preparing in the dark. This observation was also reflected by the research of Wellington [3], who found that students are often confused about the procedures of the defense, the role of the supervisor, and the possible outcomes. The main source of information for students is from friends who have already passed. Much of the students' prior knowledge of the defense is "shaky and ill-founded".

If the $\mathrm{PhD}$ defense is an integral part of a $\mathrm{PhD}$ examination, it follows that one could fail one's PhD after an unsuccessful defense. Jackson and Tinkler [7] found that failing is indeed possible in $60 \%$ of 20 British institutions. On the other hand, Mežek and Swales [4] indicated that, since the thesis is printed and distributed prior to the defense, failing a defense is uncommon in Sweden and Belgium. The same unwritten rule holds true for the Netherlands. From an international point of view, there is no consensus on the purpose of the defense [8].

Even though there are written requirements for the $\mathrm{PhD}$ defense, the actual defense itself and how it is carried out often depends on the committee members, their style of interaction, and their style of examination [5]. Power struggles between a committee member and the supervisor can happen [9], and negatively affect the student [10]. Power abuses also manifest themselves [11] when a committee member requires the candidate to add significant work related to the committee member's "pet field," and when the former requires changes to a thesis that is complete, simply because said committee member wants to leave a mark on the work. Additional concerns with regard to the behavior of committee members include that, "Feminist scholarship can be ridiculed by unsympathetic examiners, interdisciplinary work can be inappropriately examined, and international students can be treated as second class citizens" [10,12]. It has been suggested [10] that when there is a larger committee (four to eight people, as in the United States), the voice of the committee will be more balanced than when one all-powerful committee member (i.e., the external examiner in the UK) drives the outcome of the defense, and the outcome of the assessment of the doctoral thesis.

Understanding the defense, the requirements associated with the defense, and the defense format is increasingly important in the context of internationalization [7]: when a committee member participates in a defense using one format, it is not possible for him to rely upon his own experiences and his tacit knowledge about such defenses, as this experience is a function of the defense format.

When a defense is carried out according to all university rules and in all fairness, it can still go wrong because of a wrong interpretation of the expectations. Remenyi [13] describes a defense where the candidate almost failed as a result of him dropping his intellectual guard during the defense, acting as if he was having a jolly conversation with the committee members, and the committee members were focusing mostly on what was not in the dissertation (i.e., its weaknesses).

While the defense is an important step for doctoral candidates, research on the topic is often limited to national practices, mostly in Anglophone contexts [4], and only a few articles have explored the relation between the defense and student perception. Research on this topic is necessary, as, "If we are using vivas to assess students, then we should also assess the vivas we are using" [10]. This article addresses the relation between the defense format and student perception, using an international perspective. This relation was explored through 
the use of a survey, and the data give unique insights into the impacts of different elements of a defense format on student perception. This study is necessary, as most research has focused on the UK viva voce defense. In the light of continued internationalization-in particular, the wish to unify European PhDs and the development of new PhD programs in emerging countries-it is important to study defense practices internationally. Kyvik [14] remarked that there is virtually no research from an international comparative perspective. His study focused on four countries (US, UK, Sweden, and Norway). This study aims to broaden the scope of that work. Just as Kyvik [14] raised the question on "best practices" among various procedures, and how a mix of defense formats could be the basis for a future $\mathrm{PhD}$ assessment system, herein the international state of the practice is studied, and the defense elements are linked to the perceptions of the students. Finally, I propose the selection of the best elements.

The aim of this study is twofold: to provide further insight into the various defense practices internationally, and to evaluate the link between student perception and doctoral defense format. The main research questions were as follows: How does the doctoral defense format influence the perception of doctoral students before, during, and after the defense? Which elements of the doctoral defense format influence student perception, and which do not? Indeed, the goal of this study is not to present policy recommendations, but to shed a light on the different defense formats that are used worldwide, and the students' perceptions of these defense formats. As such, this work can be considered a first step towards critically analyzing defense formats in the light of the perception of the students that go through the defense, and these insights can then be used by universities internationally to evaluate the defense formats they use.

\section{Literature Review}

\subsection{Students' Perceptions of the Defense}

In this section, I give an overview of the existing research on students' perceptions of the defense. The cited studies all focused on one particular defense format.

Jackson and Tinkler [7] studied the students' perceptions of the purpose of the doctoral defense $(n=88)$ at two British universities. The perceived purpose of the defense was the authentication of the thesis and a range of other assessment activities. One in six candidates that responded to the questionnaire considered that the defense serves a negative function. Another survey of new doctors in psychology confirmed this finding, since it was found that while $85 \%$ of candidates passed the defense, $40 \%$ found it to be a negative experience [15]. These disillusioned candidates were equally divided between those who passed their defenses and those who were referred. A survey of recent graduates from social sciences $\mathrm{PhD}$ programs $(n=87)$ in Ireland [16] found that the mean score for defense satisfaction was 4.09 on a 1 (low) to 5 (high) Likert scale. In this study, there was, however, a relation between defense satisfaction and the outcome of the defense: students with referrals or major revisions reported a mean defense satisfaction of 1.85 as compared to minor (4.21) and no (4.80) corrections.

Jackson and Tinkler [7] also studied the perceptions of academics $(n=142)$ regarding the role of the defense. The most commonly identified purpose ( $36 \%$ of respondents) was to check the candidate's understanding and ability to produce and present research to a $\mathrm{PhD}$ standard. While committee members identified one of the purposes of the defense as providing an opportunity to offer guidance and advice to the students, this purpose was not identified by the students who responded to the questionnaire. Indeed, there seems to be a mismatch in expectations and understanding of the purposes of the doctoral defense in the UK between committee members and students.

To further explore why students who successfully passed their respective defenses may consider it an unsatisfactory process, Crossouard [17] conducted semi-structured interviews ( $n=20,14$ females and 6 males) of recently graduated doctors from eight universities in England. Some respondents focused on the defense's function of making them accustomed to "tough' academic judgment, reflecting a gendered dimension. Some 
interpreted the examining practices as aggressive, and some respondents experienced the defense itself as an aggression. The experience of the respondents during the defense sometimes resulted in an unexpected outcome. When students had a difficult defense, even though they passed or passed with minor corrections, the perception of the defense influenced their future work. One respondent was so shaken by the events that she has not been able to publish from her dissertation afterwards. In such cases, the defense completely loses its celebratory function.

A student's perception of his/her doctoral defense is related to the behavior of the committee members during the defense. The choice of committee members and their impacts on all factors of the defense are highlighted in [18]. This study looked at candidates' perceptions of the defense through semi-structured interviews $(n=18)$. Based on these interviews, it was found that committee members impacted various facets of the defense: (1) the actual defense (i.e., whether the candidate felt that he/she had the chance to properly defend the thesis, or if power struggles of the committee members dominated the defense); (2) the emotions of the candidate (i.e., committee members either induced anxiety and stress, or made the candidate feel more at ease); (3) the perceived fairness of the assessment, especially when the candidate had no voice in the selection of the committee; and (4) the practical aspects of the defense, such as scheduling of the defense. In addition, the way in which committee members evaluate students causes uncertainty, and a survey [19] of students in education $(n=84)$ found that a quarter of the students were very uncertain about what criteria might be used by the committee members.

When discussing committee members and the role of the committee, it is important to acknowledge (national) differences between committee size, composition, and function. In the Netherlands, large committees of up to eight committee members are formed, who all actively participate in the evaluation of the thesis, and in the defense itself. In the United Kingdom, the "committee" consists at its core of two examiners (one external and one internal), sometimes a chair to steer the viva proceedings, and sometimes the supervisor as an observer [12]. Finally, in Sweden [14] an independent opponent examines the doctoral candidate. The opponent does not form part of the evaluation committee. In Norway [14], a slightly different system is used: there are two opponents, but they also form part of the evaluation committee. While I use the general terms "committee" and "committee member(s)" throughout this work, the reader should keep in mind that there are differences between the roles of committee members and in committee composition due to defense formats and/or national practices.

Students for whom English is their second language may face additional challenges during the defense. Non-native English students' perceptions at a university in New Zealand were studied through interviews about the students' fears prior to and after their defenses. Eleven students were interviewed [20]. The fears prior to the defense were related to the defense format: "In institutions where the examinations are public, doctoral students may attend several oral examinations to observe the protocol; fear of their own then includes the public performance of the event. Fear under the British system is, ironically, of the lack of scrutiny: the unknown." All participants in the study agreed that the oral defense is valuable and a positive experience. This observation is important, since it represents the voice of non-native English speakers on the usefulness of the doctoral defense.

\subsection{A Review of Defense Formats}

From an analysis of 49 testimonies of doctoral defenses that I collected on my blog [21], and a review of the literature on the doctoral defense [22], I have identified five key elements of the doctoral defense format. The first key element of the defense is whether the thesis is published before or after the defense. If the thesis is published before the defense, it is approved by the committee beforehand, and the committee cannot require changes to the thesis after the defense. On the other hand, when the thesis is published after the defense, a variety of outcomes of the defense are possible, and these outcomes are related to the levels of change that could be necessary for the thesis [11]. The timeline for 
graduation and awarding of the doctoral degree is less uncertain if the thesis is published after the defense.

The second key element of the doctoral defense is whether the defense is oral or written. A written defense (examination report) is often used in Australia [23] and South Africa $[11,24,25]$, where the assessment then fully lies in the evaluation of the thesis [26], the subsequent rebuttal of the comments of the committee members, and the revised version(s) of the thesis. While in these countries, the written defense format has been the format of choice because of their geographical isolation, there is a movement towards using an oral defense through videoconferencing tools. The main difference between a written and oral defense lies in the way the candidate interacts with the committee members. More formal replies exist in the written format, and there is a session of answering a variety of questions in the oral format.

The third key element of the doctoral defense is whether the defense is a one-step or two-step defense. A two-step defense is when the format consists of two defenses-often a closed defense with only the committee, and a public defense where friends, family, colleagues, and other interested people are welcome. These two steps can take place on the same day, as is common in the United States [4,27], where a part of the defense is private so that the committee members can ask more in-depth questions. The two steps can also be separated out into two events, as is common in Belgium [28], where the private defense is followed by publication of the thesis, and ultimately the public defense. In a one-step defense, all aspects of the defense take place on the same day and with the same constellation of audience and committee members.

A fourth key element of the defense is whether it is public or private. In the strictest sense, a private defense is only between the committee and the candidate, and the public defense is open to all the public. While studying different defense formats, I learned that there are different gradations of each. For example, the private defense can be with or without the supervisor, and with or without a chair. Conversely, at some universities defenses are technically public but never advertised [29], so that they are practically private defenses. In a private defense, the committee members sometimes ask questions by going through the thesis on a page by page basis. This approach is very uncommon for a public defense, where the committee members typically focus on broader questions. The divide between public and private defenses is hotly debated due to the proposed European standardization of the PhD defense [14].

The fifth and final main difference in defense format is whether the defense format follows a fixed-time schedule, or whether the schedule and total time of the defense is at the hands of the committee. In a fixed-time schedule, there are strict rules about the total time the defense can take, the order in which committee members will ask their questions, and how much time each committee member receives for asking one or more question [30]. Candidates who face a fixed schedule know better in advance what their defense will look like, whereas those who defend on a schedule that is fully determined by the committee may not know how long the defense will last. An extreme case of such an unpredictable schedule is a defense that "has run into a second day" [11].

In addition, I have identified seven less important elements of the doctoral defense format. The first element is related to committee feedback on the thesis before the defense. Here, I make a distinction between the candidates who receive committee feedback before the defense and whose who do not. In addition, I make a distinction between those who implement the committee feedback they receive before the defense into their thesis, and those who do not or only partially include this feedback. Along the same lines, I distinguish between those who have an idea of the committee's recommendations for the thesis before the defense, and those who do not, which is an element that is of course closely related to whether the candidate received feedback in advance or not. Receiving feedback before the defense or not, and acting upon it, is closely related to whether the thesis is published before or after the defense, but there are subtle differences between defense formats. For example, in Norway [14] the thesis is published before the defense, without committee 
input, and a resubmission with minor corrections after the defense can be required. On the other hand, in the Netherlands, the thesis is published and printed before the defense, and the thesis will have received multiple rounds of comments from the committee members before it is accepted for defense [31].

A second less important element of the doctoral defense format is the presence or lack thereof of the doctoral supervisor during the defense. Watts [2] states that it is her experience that the "supportive presence of a supervisors has both psychological and practical elements and can help moderate the mood of what some students will perceive as a 'gladiatorial' contest."

A third minor element of the doctoral defense is whether the defense includes a presentation, and who makes up the audience of this presentation. Some defense formats are fully centered around a candidate's presentation [27], whereas in other defense formats, the candidate only presents to the audience, not including the committee, before the official start of the defense [31]. In other defense formats [8], the committee member who takes the lead in asking questions presents a summary of the research instead of the doctoral candidate. As such, it is important not only to explore whether the defense includes a presentation, but also to note who forms the audience of this presentation.

A fourth minor element is how the committee members participate in the defense: virtually or in person. The option for committee members to connect remotely has become more widely available over the past few years. In such a format, often part of the committee and the candidate are together in a room, and one or more committee members connect virtually [32]. During the COVID-19 pandemic, a fully virtual defense became more common, as distancing measures required committee members and the candidate to remain at home and all connect remotely to participate in the defense.

A fifth minor element is related to the dress code during the defense. Here, I distinguish between the defense formats that have a dress code, and those that do not have a dress code. For the defense formats that have a dress code, I distinguish between those that require academic togas for some or all of the participants, and those that require other formal wear.

A sixth minor element is whether the defense focuses on the research only, or includes other elements. Some defense formats include additional elements outside of the doctoral thesis research. For example, in Norway [8] candidates are also required to give a trial lecture on a different topic in their field of expertise, and in the Netherlands [33] candidates defend a set of propositions that they have developed to show their general ability to argue on different topics in public.

The seventh minor element of the defense is whether the defense includes a laudatio at the end or not. The laudatio is a congratulatory speech at the end of the defense. When a laudatio is included, it typically forms part of the final steps of the defense.

\subsection{Research Gap}

Based on the literature review, I found that research on students' perceptions of the doctoral defense has only been done within national contexts. I also learned which elements of student perception to include in the study survey.

This research looks at students' perceptions of the doctoral defense in an international context. To address the doctoral defense in an international format, I reviewed different defense formats and distilled the format into the building blocks of the defense. These building blocks then helped me to develop the survey questions about the defense format. This approach is novel, as no previous research has been done to identify the elements of the doctoral defense, nor to correlate elements of the defense format with the perceptions of doctoral students about the defense. In order to do so, I learned from the literature review that an international comparison of defense formats would be necessary, to distill the elements that make up the different defense formats, and from there, those elements could be studied in relation to the students' perceptions of the doctoral defense. 
Finally, the combination of quantitative methods with qualitative analysis of openended questions provided deeper insights into the experiences of doctoral candidates. Such approaches were used in other studies and inspired my research.

\section{Materials and Methods}

\subsection{Survey Design}

To study the relation between the doctoral defense (and the format of the doctoral defense) and the perceptions of the doctoral candidates about the defense, I carried out a survey. For this study, I obtained IRB approval number 2019-139IN through Universidad San Francisco de Quito. The survey received responses from participants between 13 July 2020 and 3 October 2020.

The survey, which is provided in its entirety in the Supplementary Materials of this article, consists of three main blocks after the opening section which contain the informed consent. The first block of questions aimed at gathering the socio-demographic data of the participants of the survey. The second block of questions addressed the defense and the different elements of the defense format. The third and final block of questions addressed the experiences of the candidates during and after the defense. The survey contained closed multiple-choice questions, $0-10$ sliding-scale (Likert scale) questions, and openended questions. The choice of the 11-point Likert scale was made because the results from an 11-point Likert scale tend to have the smallest kurtosis and have a distribution closest to normal [34]. The total number of questions in the survey was 54, and some questions were displayed only based on answers immediately prior.

To cover an array of defense formats as large as possible, the study was open to all who had defended their doctoral theses, regardless of the outcome of the defense, with the aim of including geographically diverse former doctoral candidates from all possible fields of study. The survey had no limitation on how recently the defense took place. For the question regarding the current position of the respondent, I used the ranking system of academics from the United States, using post-doctoral researcher, assistant professor, associate professor, full professor, and "other academic appointment" as the categories of academic employment.

The questions regarding the defense format were based on the elements of the defense format I had identified previously [22], and which I discussed in Section 2.2. I added a set of questions regarding the student's nativeness regarding the language in which the defense was held, based on the previous research that looked at the experience of non-native English speaking students in New Zealand [20].

The questions on student perception were constructed based on a number of sources. First of all, questions regarding emotions were included because the emotional level of the defense was identified in the literature as an important element $[16,18]$. Nervousness before, during, and after the defense was asked about. Other scales of student perception included: enjoyment of the defense, perceived importance of the defense, perceived difficulty, perceived formality, perceived seriousness of the defense [4], and ultimately the overall value of the $\mathrm{PhD}$ defense as part of the doctoral experience. Based on the literature review and the difficulties students have in identifying the purpose of the defense [7], I included a multiple-choice question on the perceived function of the defense and an open-ended question where respondents could add their perceived functions of the defense. Given the importance of the committee for the experience of the doctoral candidates, I included a question about the perceived fairness of the committee based on [18] and added a question on the perceived ability of the committee to perform a well-balanced assessment of the doctoral candidate's work [35].

The set of questions that looked at the students' perceptions and emotions also contained a set of questions that focused on the long-term impacts of the doctoral defense. The long-term affective level of the defense and how it influences the subsequent career of the candidate was identified as important in the literature [17]. To include this dimension, I looked at the four aspects of long-term influence of the defense from [7]: perception of 
academic competence, desire to continue work in the sphere of the PhD, desire to work within academia, and perception of the publishability of PhD research. I included these four aspects in the survey.

I recruited survey participants from my personal and professional network through social media and email. I am aware of the inaccuracies associated with self-reporting data and understand that the respondents represent a self-selecting convenience sample [36]. However, for the purposes of this study, which were to explore potential links between the candidates' perceptions and the defense format, to take a first step towards evidence-based best practices for the doctoral defense, and to identify routes for further research, this approach appears to have been sufficient.

As the data analysis stage of this research coincided with the COVID-19 pandemic, using an online survey was a suitable method to collect data while meeting people in person was not possible. Using the online platform also allowed me to reach a wide international sample of participants, and allowed participants to fill out the survey at a time that was convenient for them.

\subsection{Analysis Methods}

In the literature, I encountered two approaches for methodology. (1) Studies can be purely quantitative-e.g., analyzing survey results. Such studies typically focus on characteristics of the defense and the $\mathrm{PhD}$, such as percentages of students passing [37], or time to completion of the PhD [38]. The majority of studies on student perception and the doctoral defense were qualitative studies (2), based on interviews with a select number of recently graduated doctoral candidates. Since I wanted to cover the international breadth of doctoral defense formats, I opted for a mixed methodology. The focus of my work was on the quantitative aspects and the statistical correlations between the defense format and the perception of the students, but I also included open-ended questions in the survey, which I analyzed using inductive thematic analysis, so that I could learn more from the experiences of the doctoral candidates. The open-ended questions also helped to identify particularly worrying situations in some defenses.

The methods used in this work were combined qualitative and quantitative methods, more so quantitative. On the survey platform, I first reviewed each individual's response to the survey (vertical walkthrough of the data), and the separate answers per question (horizontal walkthrough of the data) to familiarize myself with the information. Next, I developed a report of the responses on the survey platform, to see the initial trends in the data.

I started the quantitative analysis by filtering out empty and incomplete surveys. Then, I developed a report of the responses of this filtered dataset on the survey platform. I exported the data from the survey platform in .csv format to open the dataset and converted it to a MS Excel worksheet. I analyzed the data in separate spreadsheets by breaking down survey responses per category of the socio-demographic information and cross-checked these results with the tables of the report and breakdowns per category developed on the survey platform. To get an initial idea of the different relationships between the categories of defense format elements and the categories of student perception, I used the cross-tabulation feature on the Qualtrics survey platform. Since the survey platform only provides the $p$-value of a chi-squared test and an ANOVA test, I used a Wilcoxon rank sum test for the analysis of two categories and a Kruskal-Wallis test for analysis of more than two categories [39]. To apply these statistical tests to the data, I first recoded text responses of the multiple-choice questions as numerical values, and then I used Matlab R2019a to carry out the statistical tests. I selected a $p$-value of $<0.05$ to indicate a strong correlation.

The responses of the open-ended questionnaire were analyzed for thematic content [40] using the methods of inductive thematic analysis [41,42]. First, I read all responses in detail and used the text analysis tool on the Qualtrics survey platform to tag emerging codes to these responses. To ensure consistency of the themes and avoid repetition, I wrote memos of the codes by hand. I then went through all codes again on the platform 
to doublecheck and merge some codes of similar meaning based on the memo. Then, I exported the codes and number of mentions to an MS Excel sheet, in which I identified the overarching themes of the various codes, and calculated the mentions of the overarching themes. In a next step, I sorted the overarching themes from most to least mentioned. The overarching themes resulted from the data analysis, and I did not have predetermined ideas or categories for the data.

\section{Results and Analysis}

\subsection{Participants}

Through the survey, I obtained a total of 296 responses with consent. These responses are anonymized and available in the public domain [43]. Of these responses, 204 respondents completed the survey, and this dataset was used for the analysis in this work. Respondents took between $2.5 \mathrm{~min}$ and $81 \mathrm{~h}$ (median $=10.6 \mathrm{~min}$ for $n=204$ ) to complete the survey. As respondents could return to their surveys at their convenience when using the same IP addresses, the longer survey times indicate that respondents returned to unfinished surveys later.

Table 1 shows the socio-demographic characteristics of the respondents of the survey, and the breakdown per field. The majority of respondents self-identified as white (72\%) and women $(64 \%), 35-44$ years old at the time of the survey (41\%), currently employed in academia (76\%), who defended between 1-5 years ago (52\%). Only for STEM fields did the majority $(71 \%)$ of respondents self-identify as men. The respondents of STEM fields were also more diverse than those the other fields, although the majority were still white $(56 \%)$, and STEM respondents had the lowest percentage (although still more than half) of current employment in academia (58\%). None of the respondents self-identified as "other" or "prefer not to say" for gender. The respondents defended their doctorates in 31 different countries around the world, representing all continents (except Antarctica). The countries with the largest numbers of respondents were the United States $(33 \%)$, the Netherlands (16\%), the United Kingdom (12\%), Canada (9\%), France (3\%), and Spain (3\%). The respondents' locations at the time of the survey were also geographically diverse, representing 34 countries from all continents (except Antarctica). Most respondents resided in the United States (30\%), Ecuador (13\%), the Netherlands (13\%), the United Kingdom $(9 \%)$, or Canada $(8 \%)$.

Table 1. Socio-demographic aspects of survey respondents, including time since defense of the doctorate.

\begin{tabular}{|c|c|c|c|c|c|c|}
\hline & $\begin{array}{c}\text { Total } \\
n=204\end{array}$ & $\begin{array}{l}\text { Life Sciences } \\
\qquad n=46\end{array}$ & $\begin{array}{c}\text { Humanities } \\
\text { and Arts } \\
n=29\end{array}$ & $\begin{array}{c}\text { Social } \\
\text { Sciences } \\
n=60\end{array}$ & $\begin{array}{l}\text { STEM } \\
n=57\end{array}$ & $\begin{array}{l}\text { Multidisciplinary } \\
\qquad n=9\end{array}$ \\
\hline \multicolumn{7}{|l|}{ Gender } \\
\hline Male & $36 \%$ & $24 \%$ & $24 \%$ & $22 \%$ & $71 \%$ & $11 \%$ \\
\hline \multicolumn{7}{|l|}{ Age } \\
\hline $25-34$ & $34 \%$ & $48 \%$ & $36 \%$ & $22 \%$ & $36 \%$ & $22 \%$ \\
\hline $35-44$ & $41 \%$ & $39 \%$ & $46 \%$ & $44 \%$ & $38 \%$ & $33 \%$ \\
\hline $45-54$ & $13 \%$ & $7 \%$ & $7 \%$ & $17 \%$ & $13 \%$ & $44 \%$ \\
\hline $55+$ & $12 \%$ & $7 \%$ & $11 \%$ & $17 \%$ & $14 \%$ & $0 \%$ \\
\hline \multicolumn{7}{|l|}{ Time since defense } \\
\hline$<1$ year & $14 \%$ & $11 \%$ & $11 \%$ & $18 \%$ & $16 \%$ & $0 \%$ \\
\hline $1-5$ years & $52 \%$ & $59 \%$ & $56 \%$ & $50 \%$ & $45 \%$ & $75 \%$ \\
\hline $6-10$ years & $17 \%$ & $17 \%$ & $15 \%$ & $17 \%$ & $18 \%$ & $0 \%$ \\
\hline$>11$ years & $17 \%$ & $13 \%$ & $19 \%$ & $15 \%$ & $21 \%$ & $25 \%$ \\
\hline \multicolumn{7}{|l|}{ Ethnicity } \\
\hline White & $72 \%$ & $70 \%$ & $82 \%$ & $85 \%$ & $56 \%$ & $67 \%$ \\
\hline $\begin{array}{c}\text { Black or African } \\
\text { American }\end{array}$ & $4 \%$ & $4 \%$ & $0 \%$ & $2 \%$ & $4 \%$ & $22 \%$ \\
\hline
\end{tabular}


Table 1. Cont

\begin{tabular}{|c|c|c|c|c|c|c|}
\hline & $\begin{array}{c}\text { Total } \\
n=204\end{array}$ & $\begin{array}{l}\text { Life Sciences } \\
\qquad n=46\end{array}$ & $\begin{array}{c}\text { Humanities } \\
\text { and Arts } \\
n=29\end{array}$ & $\begin{array}{c}\text { Social } \\
\text { Sciences } \\
n=60\end{array}$ & $\begin{array}{l}\text { STEM } \\
n=57\end{array}$ & $\begin{array}{l}\text { Multidisciplinary } \\
\qquad n=9\end{array}$ \\
\hline Asian & $8 \%$ & $7 \%$ & $4 \%$ & $3 \%$ & $18 \%$ & $0 \%$ \\
\hline Latino/Hispanic & $7 \%$ & $7 \%$ & $0 \%$ & $7 \%$ & $9 \%$ & $11 \%$ \\
\hline First Nations & $1 \%$ & $0 \%$ & $0 \%$ & $2 \%$ & $0 \%$ & $0 \%$ \\
\hline Mixed & $2 \%$ & $0 \%$ & $4 \%$ & $2 \%$ & $4 \%$ & $0 \%$ \\
\hline Other & $7 \%$ & $13 \%$ & $11 \%$ & $0 \%$ & $9 \%$ & $0 \%$ \\
\hline \multicolumn{7}{|l|}{ Current employment } \\
\hline Academia & $76 \%$ & $85 \%$ & $75 \%$ & $87 \%$ & $58 \%$ & $78 \%$ \\
\hline Industry \& Business & $14 \%$ & $13 \%$ & $11 \%$ & $7 \%$ & $25 \%$ & $11 \%$ \\
\hline Government & $4 \%$ & $2 \%$ & $4 \%$ & $5 \%$ & $4 \%$ & $11 \%$ \\
\hline Unemployed & $3 \%$ & $0 \%$ & $4 \%$ & $2 \%$ & $9 \%$ & $0 \%$ \\
\hline Other & $2 \%$ & $0 \%$ & $7 \%$ & $0 \%$ & $5 \%$ & $0 \%$ \\
\hline
\end{tabular}

Note: $n$ total of completed surveys was 204, but only 200 respondents filled out the fields in which they obtained their doctorates.

\subsection{Results of Questionnaire and Analysis}

\subsubsection{Defense Format}

In this section, I have provided a summary of the results of the survey. The majority of all respondents passed their defenses $(68.5 \%)$ or were required to make minor corrections $(28 \%)$. Only a small number of the respondents were required to make major corrections $(3.5 \%)$. None of the respondents switched fields or dropped out of their respective programs. The most commonly used term was defense (75\%), followed by viva $(18 \%)$. In some instances, other terms were used: final presentation (2\%), disputation (1\%), and nationally used terms: dissertation (German), promotie (Dutch), soutenance (French), or discussione (Italian). In most cases, the thesis was finalized after the defense (62\%), but over one-third $(37 \%)$ published their theses before the defense. In addition, two participants $(1 \%)$ indicated that they had not finished their theses at the time of the survey.

When it comes to defense format, a one-step defense was most common (80\%), but twostep defenses were used as well $(18 \%)$, and in some cases more than two steps were used (2\%). Typical two-step defenses contain a private defense, followed by thesis publication, and a final, public defense. The vast majority (99\%) of the respondents went through oral defense, but two respondents sat the defense in written format (one in Mexico and one in South Africa). Over half of the respondents (57\%) had public defenses, over a quarter $(28 \%)$ had private defenses, and the remaining group (15\%) had both in a two-or-more-step defense.

Over half of the respondents (55\%) indicated that the time spent during the defense was driven by the committee and their questions, over a third (38\%) of the participants had a defense format with a fixed schedule, and the remaining respondents selected "Other, please explain." These explanations included:

"It was semi committee driven. It was expected to not last much longer than an hour but no fixed end time."

"Presentation was fixed, then discussion with the committee was time free."

"40-50 min showing my results followed by approximately 4 h of questioning."

Variations of those explanations were also given. The overall time of the defense was $1.5-2 \mathrm{~h}$ for over a third (34\%) of the respondents, $1-1.5 \mathrm{~h}$ for over a quarter $(27 \%)$ of respondents, and $2-3 \mathrm{~h}$ for over a fifth (21\%) of respondents. A minority of respondents finished their defenses in less than an hour $(12 \%)$ or in more than three hours $(5 \%)$.

A slight majority (54\%) of respondents received committee feedback beforehand. Of those who received feedback, more than half of them (52\%) implemented this feedback in their theses before the defense, and over a quarter $(28 \%)$ implemented the feedback partially. Over half of the respondents (53\%) did not have an idea before the defense of the 
recommendations the committee members would give, whereas a quarter $(25 \%)$ had an idea of the recommendations of all committee members, and the remaining respondents $(22 \%)$ had an idea of the recommendations of one or more committee members.

The majority $(79 \%)$ of respondents had a defense that included a presentation. For those who gave a presentation, the majority $(68 \%)$ presented to guests and a committee. Other formats included presenting only to the committee (16\%) or only to the guests $(2 \%)$. In the comments to this question, respondents indicated that their public defense was open to the public, including colleagues, students, and anybody who was interested who may not have been a direct guest of the candidate. The impact of defending during COVID-19 on the format was also described by a respondent as follows: "Typically the committee would not join, but because it was streamed and everyone was at home, they were able to see it. Usually, they're separated in a room in the building, waiting for the presentation to be over."

Committees ranged in size from two to ten committee members. The median number of committee members was five (30\% of respondents). In most cases $(73 \%)$, the supervisor was present as part of the committee, but in some cases the supervisor was part of the audience $(20 \%)$ or not present $(8 \%)$. Table 2 shows the breakdown of committee composition per field, where we can see that it is slightly more common in STEM fields to have committee members from industry or government, but of the $n=444$ logged committee members (respondents were able to select all that apply), only 17 committee members were from industry and only five from the government.

Table 2. Breakdown of committee composition per field. Note that respondents were able to select all that applied, so $n=444$ refers to the total number of selections here, provided by 204 respondents.

\begin{tabular}{|c|c|c|c|c|c|c|}
\hline & $\begin{array}{c}\text { Total } \\
n=444\end{array}$ & $\begin{array}{l}\text { Life Sciences } \\
\qquad n=107\end{array}$ & $\begin{array}{c}\text { Humanities } \\
\text { and Arts } \\
n=54\end{array}$ & $\begin{array}{c}\text { Social } \\
\text { Sciences } \\
n=128\end{array}$ & $\begin{array}{l}\text { STEM } \\
n=130\end{array}$ & $\begin{array}{l}\text { Multidisciplinary } \\
\qquad n=18\end{array}$ \\
\hline $\begin{array}{l}\text { Internal to my } \\
\text { university }\end{array}$ & $33 \%$ & $33 \%$ & $26 \%$ & $32 \%$ & $24 \%$ & $33 \%$ \\
\hline $\begin{array}{c}\text { Internal to my } \\
\text { department }\end{array}$ & $29 \%$ & $26 \%$ & $43 \%$ & $37 \%$ & $30 \%$ & $33 \%$ \\
\hline $\begin{array}{c}\text { External to my } \\
\text { university, from other } \\
\text { university }\end{array}$ & $33 \%$ & $36 \%$ & $30 \%$ & $30 \%$ & $37 \%$ & $28 \%$ \\
\hline $\begin{array}{l}\text { External to my } \\
\text { university, from } \\
\text { industry }\end{array}$ & $4 \%$ & $4 \%$ & $2 \%$ & $1 \%$ & $8 \%$ & $6 \%$ \\
\hline $\begin{array}{l}\text { External to my } \\
\text { university, from } \\
\text { government }\end{array}$ & $1 \%$ & $2 \%$ & $0 \%$ & $0 \%$ & $2 \%$ & $0 \%$ \\
\hline
\end{tabular}

Note: the total number of completed surveys was 204, resulting in $n=444$ selections, but only 200 respondents filled out answers to the fields in which they obtained their respective doctorates, resulting in $n=437$ selections of committee members in the part of the table with the breakdown per field.

In the majority of cases $(73.5 \%)$, all committee members were physically present in the room. In recent years, it has become more common for committee members to connect through video or phone conferencing software. One possible format is to have some committee members present and some connected remotely (17.5\%). The earliest registered defense of this format was in 2007 in Canada, and the majority of responses of this format were from the period 2015-2019. The option of having fully remote defenses $(9 \%)$ only became common during the COVID-19 pandemic. Generally (64\%), all committee members ask questions. In some cases, only some committee members $(10 \%)$ and/or the audience $(21 \%)$ asked questions. Four respondents clarified in the textbox that all committee members except for the supervisor(s) asked questions. Other clarifications included, "Audience holding a doctoral degree," and "During the oral presentation, the audience asked questions, then on closed quarters, all the members asked questions." 
In most cases $(87 \%)$, the defense focused on the research only. For the remaining respondents $(13 \%)$, other elements were included: questions about the general field of research, the candidate's experience with multidisciplinary research, interpretation of the results in a wider context, the propositions, science philosophy, defense of a societal project, and a discussion on supervisory issues experienced by the candidate. The majority $(57 \%)$ of respondents had a defense format without laudatio (congratulatory speech of the supervisor after receiving the outcome of the defense), and the remaining respondents ( $43 \%)$ did have a laudatio.

The majority (78\%) of defenses were held in English, and the remaining defenses $(22 \%)$ were in the languages of the countries where the respective universities were located. The language of the defense was the native language for the majority $(62 \%)$ of respondents. Over a quarter $(27 \%)$ indicated that the language was not their native language, and the remaining portion $(10 \%)$ indicating they considered themselves near-native speakers of the language.

Most respondents $(62 \%)$ and their committee members were not required to follow a dress code, whereas over a quarter (26\%) were required to use formal wear, and only a minority $(13 \%)$ were required to dress in academic togas.

\subsubsection{Student Perception}

The first aspect of student perception addressed in the survey is how nervous the student felt before the defense, during the defense, and after the defense but before receiving the outcome. Figure 1 shows that on average, students felt most nervous before the defense (median value 7 on an 11-point Likert scale from 0 to 10, average $=6.79$ ), and then gradually less nervous during the defense (median value 5 , average $=4.84$ ), and after the defense and before receiving the outcome (median value 3 , average $=4.01$ ). The latter category, however, has the largest distribution of results.

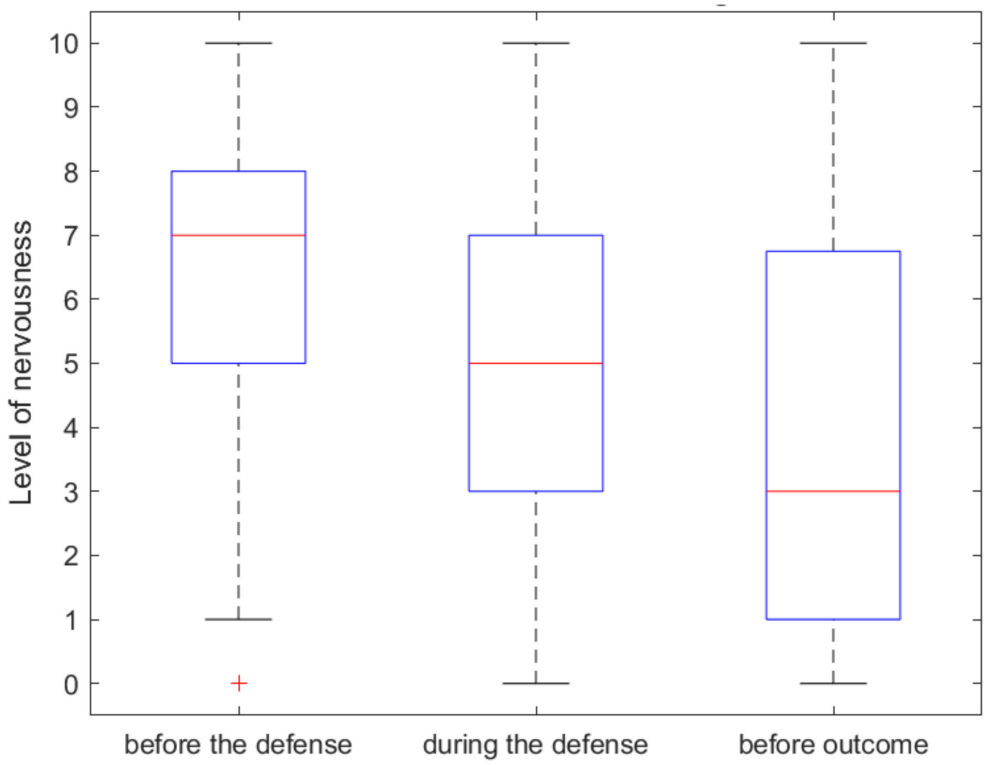

Figure 1. Boxplot of self-reported nervousness before the defense $(n=200)$, during the defense $(n=197)$, and after the defense but before receiving the outcome $(n=175)$.

The second set of elements of student perception contains how much the student enjoyed his/her defense; the perceived importance, difficulty, formality, and seriousness of the defense; and the overall value of the defense as part of the PhD experience, as expressed on an 11-point Likert scale from 0 to 10 (see Figure 2). We can see in Figure 2 that $\mathrm{PhD}$ candidates on average quite enjoyed their defenses (median value 7 , average $=6.63$ ), found their defenses moderately difficult (median value 6 , average $=5.90$ ), considered them quite important (median value 8 , average $=7.48$ ), perceived their defenses as formal (median 
value 7 , average $=6.40$ ) and serious (median value 6 , average $=6.36$ ), and overall found the $\mathrm{PhD}$ defense to be a valuable part of the PhD experience (median value 8 , average $=7.46$ ).

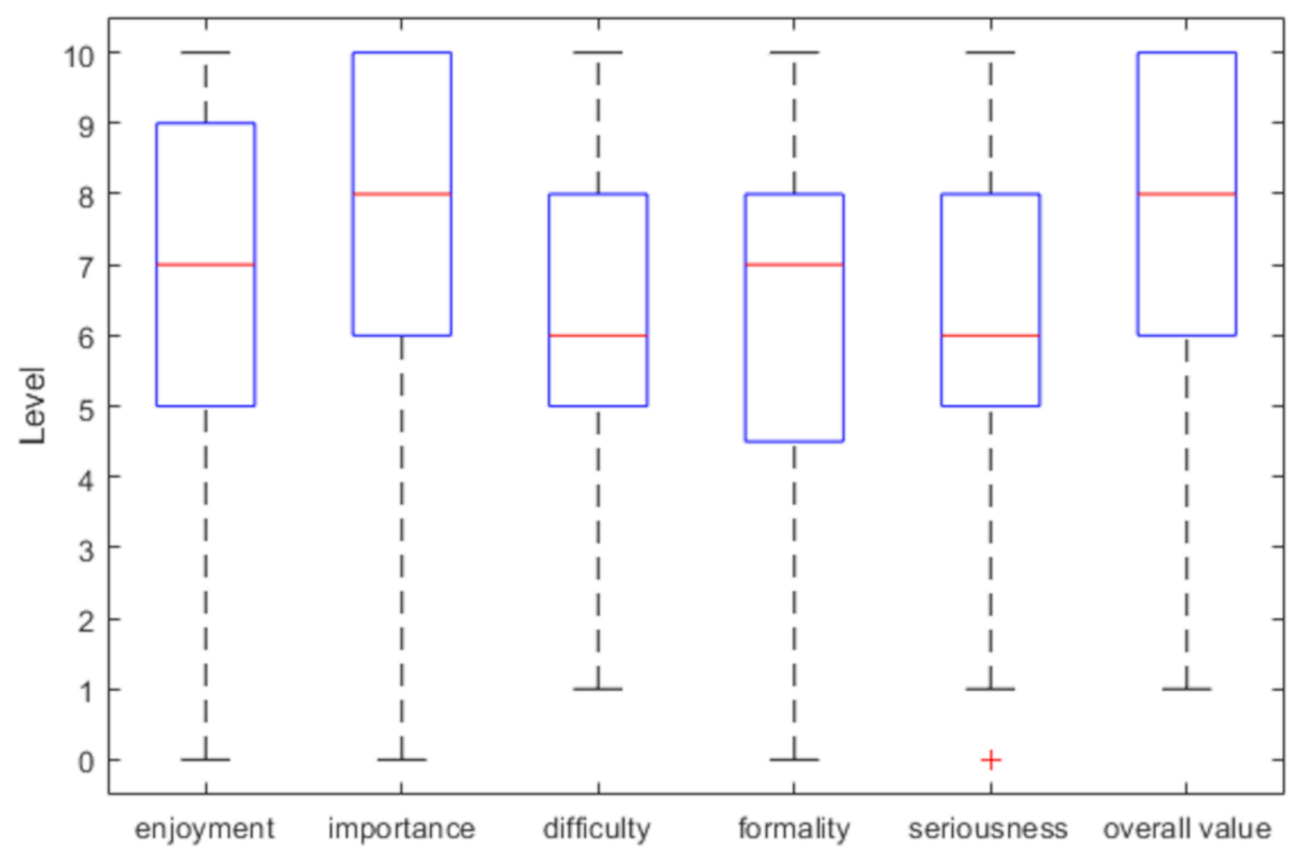

Figure 2. Boxplot of student perception of the defense: enjoyment of defense $(n=198)$, perceived importance of the defense $(n=200)$, difficulty of the defense $(n=201)$, formality of defense $(n=200)$, seriousness of defense $(n=199)$, and overall value of the oral defense as a part of the doctoral experience $(n=201)$.

The next element of student perception that I explored is how fair and how suitable for making well-balanced assessments the candidates perceived their committees to be. Table 3 gives an overview of the responses, and a breakdown per field. In the humanities and arts and the multidisciplinary fields, the lowest perceived fairness of the committee (64\% and $67 \%$, respectively) and the lowest perceived suitability of the committee $(68 \%$ and $44 \%$, respectively) were present. The poor suitability of a committee in a multidisciplinary field could potentially be a result of not all aspects of the multidisciplinary work being reflected by the committee's composition.

Table 3. Perceptions of committee suitability. $n=200$ for the question “Did you consider your committee fair?" and $n=202$ for the question "Did you consider your committee suitable for making a well-balanced assessment of your work?" There is a breakdown of responses per field.

\begin{tabular}{|c|c|c|c|c|c|c|}
\hline & Total & Life Sciences & Humanities and Arts & Social Sciences & STEM & Multidisciplinary \\
\hline \multicolumn{7}{|c|}{ Did you consider your committee fair? } \\
\hline & $n=200$ & $n=45$ & $n=28$ & $n=60$ & $n=56$ & $n=9$ \\
\hline Yes & $84 \%$ & $89 \%$ & $64 \%$ & $87 \%$ & $89 \%$ & $67 \%$ \\
\hline To some extent & $15 \%$ & $11 \%$ & $32 \%$ & $12 \%$ & $11 \%$ & $33 \%$ \\
\hline No & $1 \%$ & $0 \%$ & $4 \%$ & $2 \%$ & $0 \%$ & $0 \%$ \\
\hline \multicolumn{7}{|c|}{ Did you consider your committee suitable for making a well-balanced assessment of your work? } \\
\hline & $n=202$ & $n=46$ & $n=28$ & $n=60$ & $n=57$ & $n=9$ \\
\hline Yes & $80 \%$ & $83 \%$ & $68 \%$ & $83 \%$ & $84 \%$ & $44 \%$ \\
\hline To some extent & $19 \%$ & $15 \%$ & $32 \%$ & $13 \%$ & $16 \%$ & $56 \%$ \\
\hline No & $1 \%$ & $2 \%$ & $0 \%$ & $3 \%$ & $0 \%$ & $0 \%$ \\
\hline
\end{tabular}

Note: The total number of respondents for the first question was 200, but only 198 of these filled out the fields in which their doctorates were obtained. Similarly, for the second question, the total number was 202, and 200 of these filled out their respective fields. 
The perceptions of the purposes of the defense are shown in Table 4, including a breakdown per field. The largest number of selections were for the function of examination, followed by confirmation and rite of passage. In the category "other," some worrying signs were given, such as "a chance for senior academics to eat their young," "confrontation," "payback for personal reasons," and "organizational nightmare." The survey also included an openended question on how the participants would describe the purpose of the defense in their own words. I used inductive thematic analysis on these 164 responses, which resulted in the following overarching themes, ordered from most to least often mentioned: evaluating the ability of the researcher, receiving input from the committee, a formality, confirming authorship, evaluating the impact of the work, defending the research, a presentation, a positive experience, a graduation requirement, closure, reflection on the research, a scholarly discussion, a celebration, a confirmation, an examination, a moment to share with friends, family, and colleagues, a negative experience, a ceremony, important for the grading of the $\mathrm{PhD}$, evaluating the ambassador role of the candidate, discussion of future work, a rite of passage, a time when the chair is crucial, a review, a show piece, a moment when you want to do well, an event that requires effort, an event that requires proper preparation, a time to link back to the coursework, an obligation, and a serious event. Again, in the category of negative experiences, worrying signals were given: "Academic hazing".

Table 4. Breakdown of perceived purpose of the defense. Note that respondents were able to select all that applied, so $n=$ 536 refers to the total number of selections here, provided by 204 respondents.

\begin{tabular}{|c|c|c|c|c|c|c|}
\hline & $\begin{array}{c}\text { Total } \\
n=536\end{array}$ & $\begin{array}{l}\text { Life Sciences } \\
\qquad n=122\end{array}$ & $\begin{array}{l}\text { Humanities and Arts } \\
\qquad n=80\end{array}$ & $\begin{array}{l}\text { Social Sciences } \\
\qquad n=150\end{array}$ & $\begin{array}{c}\text { STEM } \\
n=152\end{array}$ & $\begin{array}{l}\text { Multidisciplinary } \\
\qquad n=25\end{array}$ \\
\hline Examination & $29 \%$ & $30 \%$ & $29 \%$ & $29 \%$ & $30 \%$ & $32 \%$ \\
\hline Ceremony & $16 \%$ & $20 \%$ & $15 \%$ & $9 \%$ & $20 \%$ & $16 \%$ \\
\hline Celebration & $13 \%$ & $15 \%$ & $14 \%$ & $10 \%$ & $13 \%$ & $12 \%$ \\
\hline Confirmation & $20 \%$ & $19 \%$ & $18 \%$ & $21 \%$ & $20 \%$ & $20 \%$ \\
\hline Rite of passage & $20 \%$ & $16 \%$ & $23 \%$ & $26 \%$ & $14 \%$ & $20 \%$ \\
\hline Other & $3 \%$ & $2 \%$ & $3 \%$ & $5 \%$ & $2 \%$ & $0 \%$ \\
\hline
\end{tabular}

Note: the respondents numbered 204, resulting in $n=536$ selections, but only 200 respondents put down the fields in which they obtained their doctorates, resulting in $n=529$ selections of functions for the defense in the part of the table with the breakdown per field.

"For me, a defense is the culmination of years of research and work. The committee treated me like some kind of an amateur or imposter, rather than an expert in my field."

"Well, the purpose of what my defense was supposed to be and what it ended up being are two different things. I had attended someone else's defense before mine and based on that experience, and the information from my advisor, I was under the assumption that the defense was a way to explain my research and to provide clarity on anything that my committee had questions about. Additionally, to explain any limitations. Unfortunately, 2 of my committee members did not really provide me with the opportunity to do either of these things. The first committee member lectured me for his 20 minute time limit about how he did not like how I interpreted one of the films I mentioned (not the ones I actually analyzed - the film in question was just foundational). The other committee member, also male, lectured me about feminism (my dissertation's sub-title partially includes 20th/21st century Post-modern Feminism) and went over his time soooo much that my advisor was only able to ask 1 question, since she went last. Additionally, both the male committee members wanted extensive edits that had not be mentioned previously and were not possible given the time until I had to submit my final draft, so my advisor told me to do what I could and what I felt was most useful."

To evaluate the students' perceptions of the long-term impacts of their PhD defenses on themselves and their careers, the respondents answered four questions [7]: "How did your defense influence your perception of your academic competence?" "How did your defense influence your desire to continue to work in the sphere of your PhD research?" "How did your defense influence your desire to work in academia?" "How did your 
defense influence the perception on the publishability of your research?" The three options for these statements were "XXX increased after my defense," "XXX decreased after my defense," and "XXX was not affected by my defense," where XXX refers to one of the four dimensions explored in these questions. Figure 3 gives an overview of the results. We can observe here that the majority of candidates (57\%) perceived an increase in their perception of their academic competence after their defense. The desire to continue to work in the sphere of the PhD research and in academia was unaffected by the defense for most respondents $(60 \%$ and $62 \%$, respectively), and the majority of respondents $(52 \%)$ also did not see an impact of the defense on their perceptions of the publishability of their work. We can observe as well that almost a tenth of respondents (8-9\%) reported long-lasting negative perceptions and career impacts after the defense.

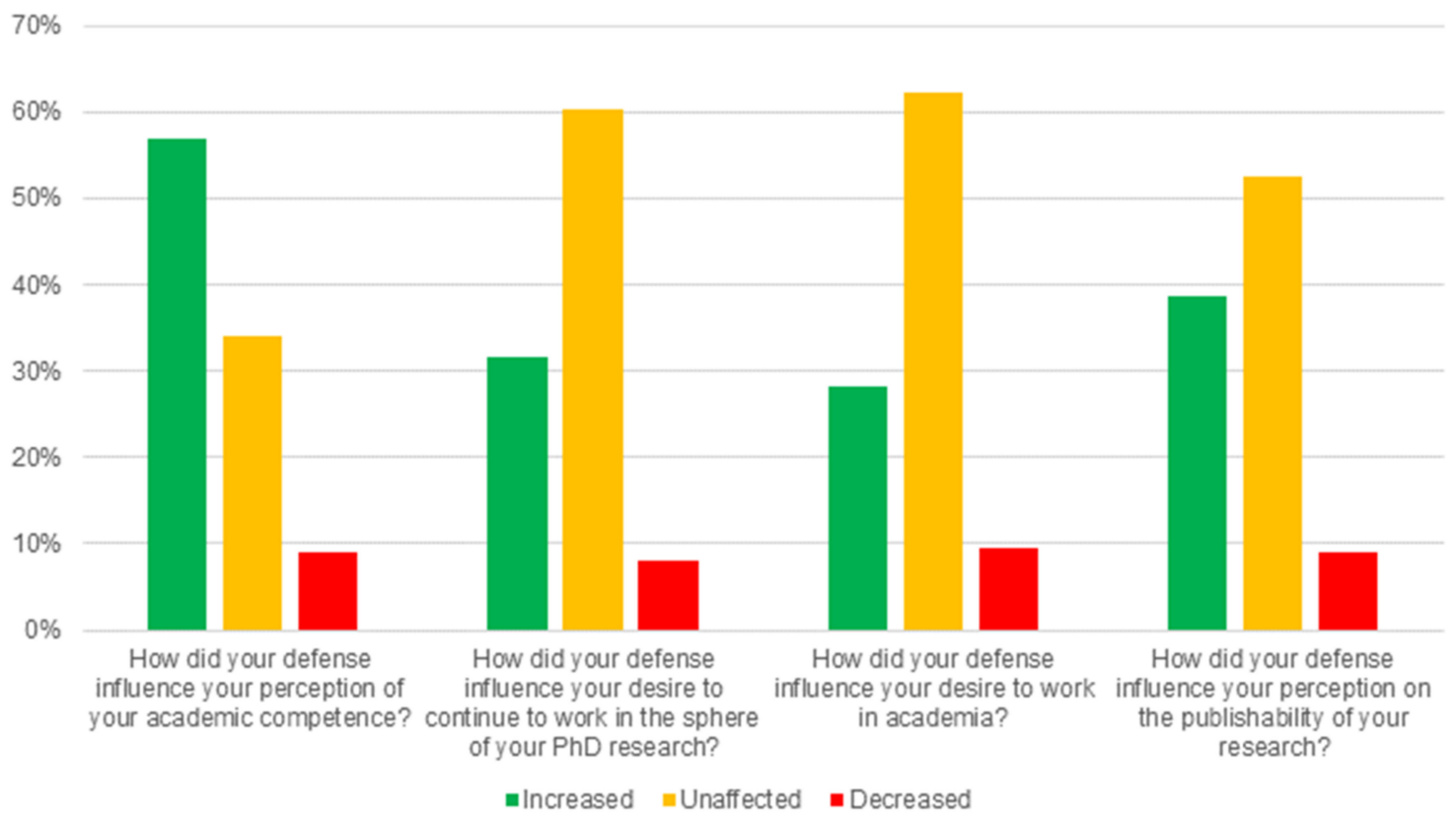

Figure 3. Long-term impacts of the $\mathrm{PhD}$ defense on student perception; $n=202$ for all four questions.

The survey ended with an open-ended question: "In hindsight, would you have prepared differently for the defense? Describe what you would have done differently." I used inductive thematic analysis on these 139 responses, which resulted in the following overarching themes, ordered from most to least often mentioned: nothing different, different preparation, different mindset, lack of support, positive experience, present contents differently, research and writing issues, different committee interaction, negative experience, defense would be different nowadays, different clothes, tech issues, the defense is unpredictable, and use different products at the defense. In the category of different presentation were comments of those who felt they spent too much time preparing and those who wanted to prepare by reading different material. In the lack of support category were those who reported to have received not enough support from their supervisor, chair, or university in the preparation for the defense. In the category of different committee interactions, there were issues with the composition and behavior of the committee members, such as:

"I would have jettisoned at least one member of the defense committee who had little to no understanding of the topic and clearly did not read my work. Their presence was a hindrance to the entire proceeding and they were also late, which put the defense in jeopardy of being cancelled."

"I don't think I would have prepared differently, but I think that if my committee members had actually done in the defense what was supposed to happen (asking me to clarify, 
etc.), I think it would have been a very valuable experience. I had prepared to clarify my arguments. I was not prepared to explain a very knick-picky element of an introduction to a chapter. I was also not prepared to listen to someone who is not an expert in feminism explain how I should have approached it. These were not things that a) should have happened, and b) that anyone could have been prepared to defend against or explain."

"My committee members almost uniformly asked me questions that were not central to my dissertation, for example, about footnotes or asides, and on the whole, I did not feel like I was asked to defend my dissertation because I did not feel their questions were actually very serious. It was very disappointing. Now, I always tell people to prepare by reviewing their footnotes."

The unpredictability of the committee and the defense is also reflected by:

"No, in the UK is very much driven by the examiners so the experience can vary quite a lot depending on whom you get as examiner, whether is from the supervisor's academic circle, etc so it is difficult to anticipate."

In the negative experiences category, I also sorted these worrying comments: "I don't think I could have - I had had no reason to believe I would be asked to revise and resubmit until I was actually there," "Everything from the beginning," and "I wouldn't have prepared differently. I wish the oral presentation were eliminated. It is over-emphasized in the US and doesn't serve a real purpose." For those who had a positive experience and would not have prepared differently, the following comments are representative:

"I believe that practicing my presentation and reading "how to" guides for preparing for my defense helped me to prepare. Additionally, knowing myself and how I react under performance pressure (public speaking) helped me to know how to prepare for my defense. I don't think I would have done it differently."

"No. I was well-advised, knew what was expected and it went exactly as planned. I was not surprised by anything, was confident in my work, and felt it went well."

\subsection{Associations among Defense Format and Student Perception}

\subsubsection{Matrix of Analyses}

To analyze the associations among defense format and student perception, I first set up the analysis matrix shown in Table 5. This matrix identified 16 elements of the defense format, whose correlations with the 14 aspects of strong student defense needed to be evaluated, resulting in 224 analyses. These 16 elements are the four of the five major elements and the seven minor elements identified in Section 2.2, expanded with the following three elements: committee composition, language nativeness, and who asked the questions during the defense. Given the small number of respondents with a written defense, this variable was not correlated with student perception. The minor element of committee feedback and prior recommendation was separated into two elements: whether the student received committee feedback before the defense or not, and whether they had an idea of the recommendations prior to the defense or not. Moreover, from the comments in the "Other, please explain" textbox to the question of whether the defense followed a fixed-time schedule or the timeline was committee-driven, I could derive that this question was not clear for all participants. Therefore, I analyzed the relation with the duration of the defense from the students' perspectives. The assumption was that shorter defenses were those with fixed-time schedules, whereas longer defenses were at the discretion of the committee members. 
Table 5. Matrix of analysis between categories of defense format and categories of student perception.

\begin{tabular}{ccc}
\hline & Characteristics of Defense Format & Student's Perception of Defense \\
\hline 1 & Thesis publication before or after defense & Nervousness \\
2 & One- or two-step defense & Enjoyment \\
3 & Public or private defense & Perceived fairness of committee \\
4 & Duration of defense & Perceived committee balance \\
5 & Committee feedback before defense or not & Perceived importance \\
6 & Prior idea of recommendation & Difficulty of defense \\
7 & Defense with or without presentation & Formality of defense \\
8 & Number of committee members & Seriousness of defense proceedings \\
9 & Presence of supervisor & Purpose of defense \\
10 & Committee composition & Perceived academic competence after defense \\
11 & In-person or remote defense & Desire to continue in field after defense \\
12 & Language nativeness & Desire to remain in academia after defense \\
13 & Defense dress code & Perceived publishability of research after defense \\
14 & Source of questions & Overall perception of defense as valuable experience \\
15 & Defense about research only or including other elements & \\
16 & Laudatio or not & \\
\hline
\end{tabular}

Preliminary analyses consisted of setting up cross-tabulations on the survey platform, which included percentages per category, statistical tests of these percentages, the chisquared test $p$-value, the averages per category, and the ANOVA $p$-value. While I did not use these crude statistical tests for the final analysis, I evaluated these statistical tests and the percentages and averages per category to identify which entries of the analysis matrix would be suitable for an in-depth analysis in Matlab, which required assigning the text values to numerical categories for processing in Matlab. I wrote separate code for the different characteristics of the defense format and included programmed loops to remove "NaN" results.

\subsubsection{Major Elements of the Defense Format}

The analyses indicate that perceptions were more positive when the thesis was published before the defense, as compared to those who published their theses after their defenses. I carried out a Wilcoxon rank sum test for the categories of publishing the thesis before and after the defense ( $n=195$ respondents) in correlation to various dimensions of student perception. In the analysis, I left out the $n=2$ respondents who indicated that they had not yet submitted their theses. Those who published their theses before the defense enjoyed the defense more (average $=7.714$ ) than those who published afterwards (average $=6.112$ ). The $p$-value is $1.97 \times 10^{-5}$ and $h=1$, indicating that the null hypothesis can be rejected. In the following analyses, I will only report the $p$-values for the cases with $h=1$. Those who published their theses before the defense perceived their defenses as less important (average $=7.041$ ) than those who had not yet published their theses (average $=7.854)(p=0.025)$. These observations can be explained by understanding that the defense is an important step of feedback for those who submit their theses after the defense, and since the uncertainty about the outcome is higher, they may also enjoy their defenses a bit less. Those who published their theses before their defenses perceived them as more formal (average $=7.466$ ) than those who published after their defenses (average $=5.758$ ), with a $p$-value of $2.7 \times 10^{-6}$ and $h=1$. This observation can be explained because when the thesis is already approved by the committee and published, the defense proceedings can be perceived as more of a formality. Of those who published their theses before the defense, $66 \%$ perceived it as a ceremony, compared to $27 \%$ of those who published afterwards. In turn, $43 \%$ and $29 \%$, respectively, thought of the defense as more of a celebration. In total, $67 \%$ of those who published their theses before their defenses reported increased academic competence after their defenses, compared to $52 \%$ of those who published their theses after their defenses $(p=0.044)$. Conversely, more $(46 \%)$ of those who published their theses after their defenses report some improvement in their 
perception of the publishability of their work than those who published before the defense $(27 \%, p=0.005)$, which can be explained by the fact that a defense with a positive outcome will be followed by the publication of the thesis. Finally, those who published their theses before their defenses found it a more valuable experience than those who published after (average values of 8.096 versus $7.176, p=0.0053$ ).

Overall, having a one- or two-step defense did not impact the students' perceptions much. The only difference is that those with a two-step defense, they perceived it as more of a ceremony than those with a one-step defense ( $56 \%$ and $39 \%$, reps.). This observation can be explained by the fact that the second step in the two-step defense is indeed more ceremonial in nature, as the student has already passed the internal defense.

Those with private defenses perceived said defenses to be more important than those with public ones did (average of 8.018 and 7.08, respectively, $p=0.042$ ). Those with public defenses perceived their defenses to be more formal than those with private defenses did (averages of 6.722 and 5.407, respectively, $p=0.0018$ ). Of those who had public defenses, almost half $(48.7 \%)$ perceived it as a ceremony, compared to only $21.1 \%$ of those with private defenses. The perception of academic competence decreased more often in cases of private defense $(17.9 \%)$ than public defense $(2.6 \%)$, but there was no statistically relevant relation between private or public defense and perceived academic competence after the defense. While the literature points towards more potential power abuse in the case of a private defense, the data from this survey do not show a clearly improved perception of the defense for the students who had public ones as compared to those who had private ones.

The impact of the duration of the defense on the student perception was limited, and only a few dimensions of student perception seem to correlate with the length of the defense. Figure 4 shows that the perceived formality of the defense decreased as the duration increased ( $p=0.007$ with a Kruskal-Wallis test). There was, however, no influence of the duration of the defense on the perceived difficulty. Shorter defenses can be more formal in nature and serve as confirmations, and longer defenses may feature more in-depth questioning by the committee. This explanation is also supported by the results regarding the purpose of the defense: of those who had defenses of less than an hour, $54.2 \%$ perceived the defense as an examination, compared to $90 \%$ of those with defenses of over three hours. Conversely, $75 \%$ of the respondents who had defenses of less than an hour described its purpose as a ceremony, compared to $33.3 \%$ of those with defenses between 1.5 and $2 \mathrm{~h}, 20.9 \%$ of those with defenses between 2 and $3 \mathrm{~h}$, and $60 \%$ of those with defenses of more than $3 \mathrm{~h}$.

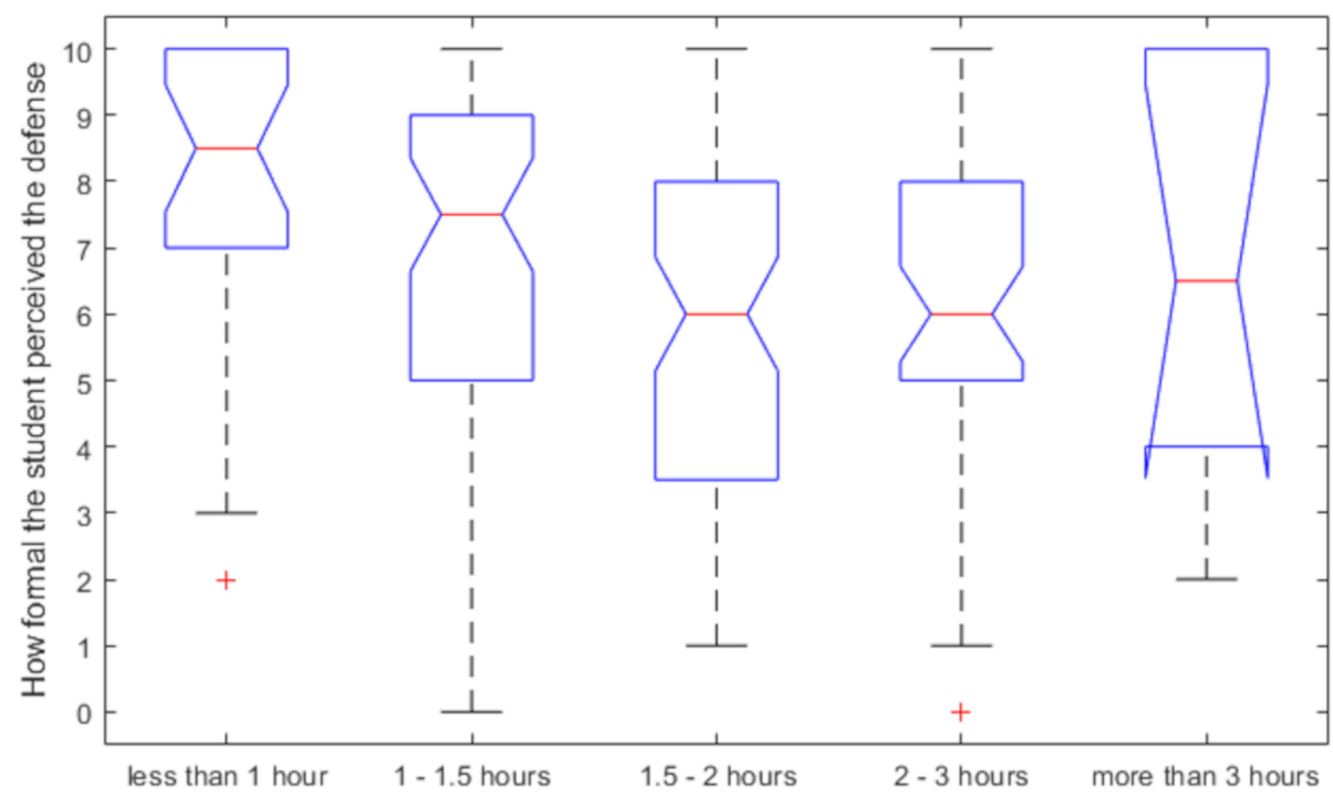

Figure 4. Relation between how formal the student perceived the defense and defense duration. 


\subsubsection{Minor Elements of the Defense Format}

Receiving committee feedback before the defense improves the student's perception. Those who received committee feedback before the defense enjoyed the defense more than those who did not (average of 7.19 versus 6.00, $p=0.0019$ using a Wilcoxon rank sum test). Those who received committee feedback before the defense considered it more of a ceremony $(48.6 \%)$ than those who did not $(34.0 \%)$ and more of a celebration $(41.3 \%)$ than those who did not $(25.5 \%)$. When a student has already received feedback, and potentially also already incorporated this feedback, the student experiences less uncertainty before and during the defense.

Similarly, the candidates who had an idea of the recommendations of some or all committee members prior to the defense had more positive perceptions that those who did not. Those who did not have an idea of the recommendations for their theses and defenses were more nervous after their defenses, before hearing their outcomes (average $=4.68$ on a $0-10$ Likert scale) than those who knew the recommendations from all (average $=$ 2.86 ) or some (average $=3.65$ ) of their committee members ( $p=0.0028$ using a KruskalWallis test). Those who knew the recommendations of all committee members enjoyed themselves more (average $=7.45$ ) than those who knew of some (average $=6.84$ ) or none (average $=6.16)(p=0.0246)$. Similarly, those who did not know the recommendations experienced the defense as more important (average $=8.047$ ) than those who knew of some (average $=7.372)$ or all (average $=6.306)(p=0.0008)$. On the other hand, those who knew the recommendations of all committee members perceived the defense as more formal (average $=7.245)$ than those who knew of some (average $=6.045)$ or none (average $=6.159)$ $(p=0.0301)$. The observations of students' sentiments are in line with the result that those who already knew the recommendations of all committee members perceived the defense as more of a ceremony $(66.7 \%)$ than those who knew of some $(47.7 \%)$ or none $(28.0 \%)$ of the committee members' recommendations. Those who knew the recommendations of all committee members also perceived the defense as more of a celebration (51\%) than those who knew none (18.7\%). The result from those who knew some of the committee members' recommendations is similar (52.3\%) to that from those who knew of all committee members' recommendations (51\%). These observations can be explained because a student who knows some or all of the recommendations of the committee members is faced with less uncertainties and potential surprises during the defense.

The committee composition seems not to have an influence on most aspects of student perception. Figure 5 shows the boxplot of the overall value of the defense broken down by the presence of different categories of committee members. While the trend is the same for all categories, a markedly lower value is associated with the presence of a committee member internal to the department. Potentially, a committee member who is internal to the department has worked too closely together with the candidate to provide quality feedback. However, more research on committee composition is necessary, and more defenses in which members from the government and industry participated should be studied and correlated with student perceptions.

Student perception is not correlated with who asked the questions during the defense: all the committee members, some committee members, or any combination in which the audience was also allowed to ask questions. This observation may be explained by the fact that it is not the person who asks the question that matters, but the question in itself.

Having a supervisor present during the defense (as committee member or as member of the audience) has a positive impact on the perceptions of the student. When the supervisor was present as part of the committee (average $=6.671$ ) or audience (average $=6.676$ ), the student felt less nervous before the defense than when the supervisor was not present (average $=8.00)$; see also Figure 6a ( $p=0.0699$ using a Kruskal-Wallis test, indicating only a weak correlation). During the defense, the presence of the supervisor seems not to have mattered so much; see Figure $6 \mathrm{~b}$. After the defense, not having the supervisor present resulted in more nervousness (average $=5.00$ ) than having the supervisor as part of the 
audience (average $=4.813$ ) or committee (average $=3.698),(p=0.053$, indicating only a weak correlation); see Figure 6c.

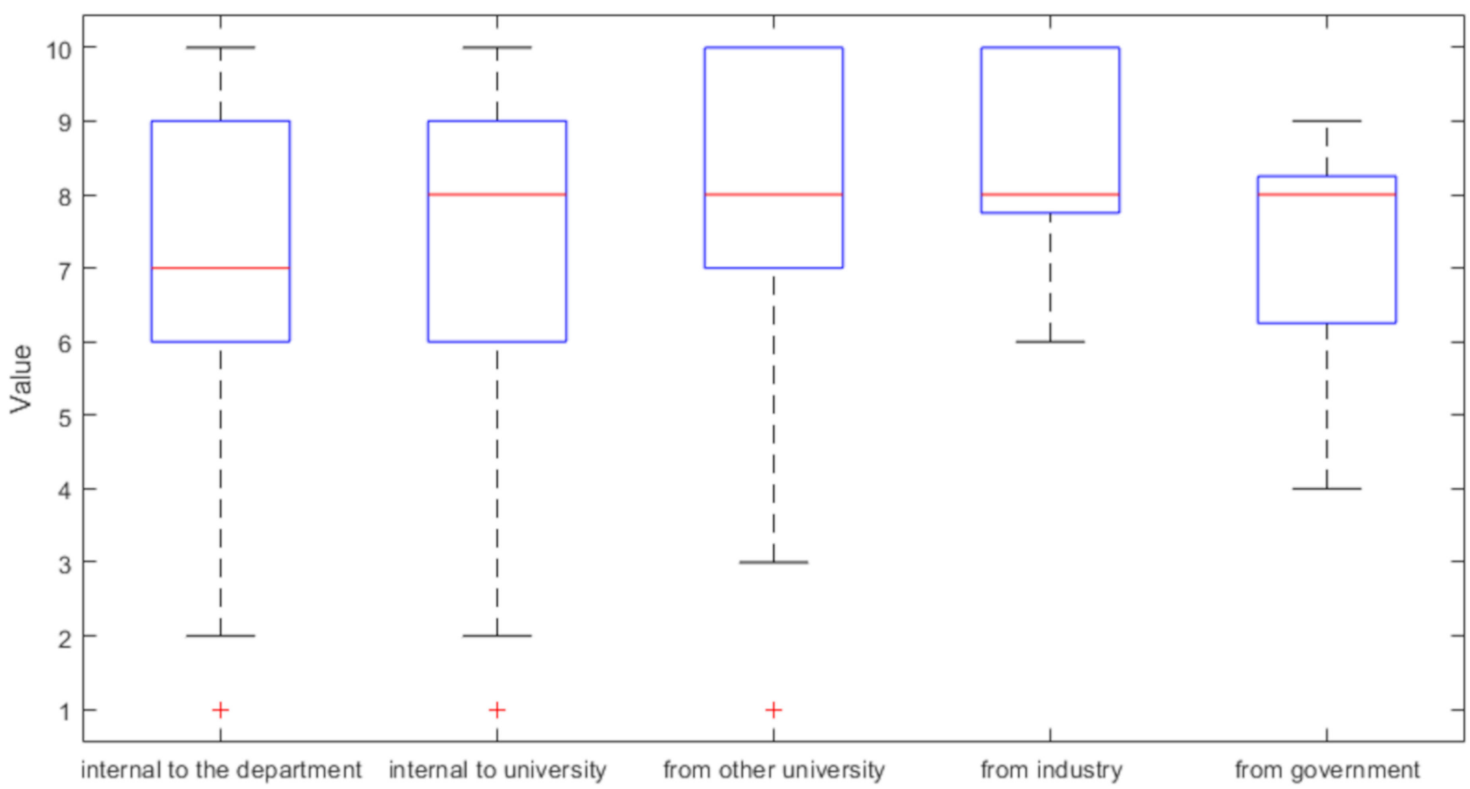

Figure 5. Value of defense as a function of committee composition.

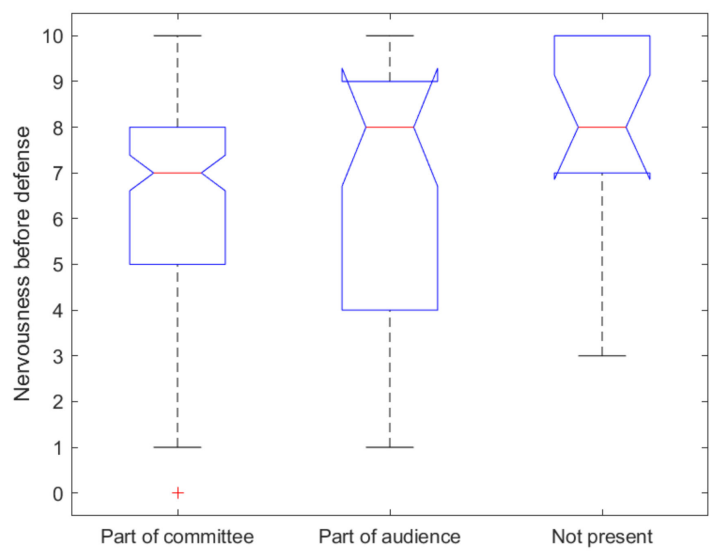

(a)

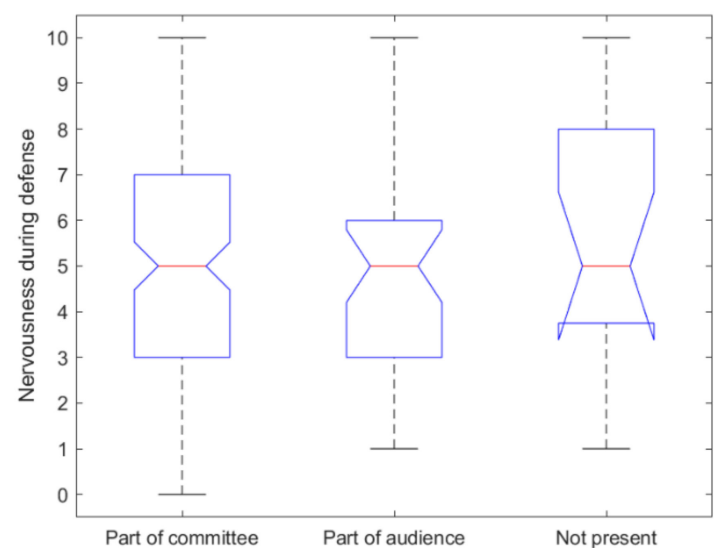

(b)

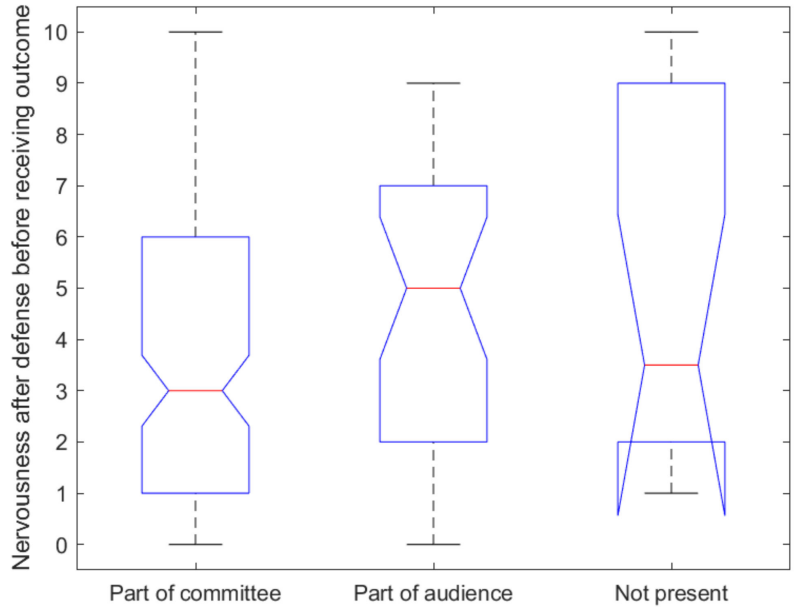

(c)

Figure 6. Relation to nervousness (on a 0-10 Likert scale) and supervisor presence: (a) before the defense, (b) during the defense, and (c) after the defense and before receiving the outcome. 
It seems that those whose supervisors were not present during the defense enjoyed the defense less (average was 6.707 for when the supervisor was present as a committee member or in the audience, and 5.706 when the supervisor was not present), but a statistical correlation was not found. When the supervisor is not present, the defense is perceived as more important (average $=8.941$ ) than when the supervisor is part of the committee (average $=7.194)$ or part of the audience (average $=7.868)(p=0.0075)$. The defense is perceived as more formal when the supervisor is present (average $=6.322$ when the supervisor is part of the committee, and average $=7.316$ when the supervisor is part of the audience) than when the supervisor is not present (average $=4.938)(p=0.0051)$. The student perceives the defense as more of a ceremony when the supervisor is part of the committee $(44.90 \%)$ or audience $(44.74 \%)$ than when the supervisor is not present $(11.77 \%)$, and more as a celebration when the supervisor is present $(38.10 \%$ when the supervisor is part of the committee, $26.32 \%$ when the supervisor is part of the audience, and $17.65 \%$ when the supervisor is not present). These sentiments can be explained by the emotional support that the presence of a supervisor gives to a student, regardless of the active participation in the defense.

Having a presentation as part of the defense format seems to have had a positive impact on the students' perceptions, but significant correlations could not be found. Those who had a defense format with a presentation perceived their defenses as less important (average $=7.323$ on a $0-10$ Likert scale) than those who did not give presentations (average $=8.071$ ), but the Wilcoxon rank sum test $p$-value was 0.0787 and $h=0$, so a correlation between perception of importance and presentation cannot be inferred. The defenses that included a presentation were perceived more ceremonious $(45.96 \%)$ than those that did not $(26.19 \%)$. The defenses that did not have a presentation had more negative impact on the perception of academic competence (19.51\%) than those that did not $(6.21 \%)$, but a statistical correlation could not be confirmed $(p=0.6846, h=0)$. Similarly, the defenses that included a presentation more greatly increased the desire to work in the field of the $\mathrm{PhD}$ research $(35.4 \%)$ than those that did not include a presentation $(17.07 \%)$, but a statistical correlation could not be confirmed $(p=0.2868, h=0)$. While these results show no statistical significance, having a presentation as part of the defense format may be positive, because it allows the student to prepare for the presentation in advance, as a certain element of the defense, and, when the discussions center around the presentation and the presentation materials, the student may also feel that they have a better grip on the contents of the defense. These explanations are speculations and require further in-depth research on the function of a presentation during the defense and how a presentation potentially steers discussions during a defense.

Overall, there seems to be no correlation between virtual or in-person defense and student perception. When all committee members were present, the defense was perceived as more formal (average $=6.678)$ than when some (average $=5.714$ ) or all (average $=5.500)$ were connected remotely; see Figure $7(p=0.0547)$. The overall value of the defense was rated slightly lower for those who had a fully remote defense (average $=6.889$ ) as compared to those who had some committee members connecting remotely (average $=7.324$ ) or all members present (average $=7.605$ ), but the statistical test showed no significance. Other dimensions of student perception did not correlate with whether the defense was in-person or remote. This observation may indicate that in the COVID-19 pandemic, all parties involved managed to deliver a more or less similar experience to the students defending their doctoral thesis as before distancing measures were in place. 


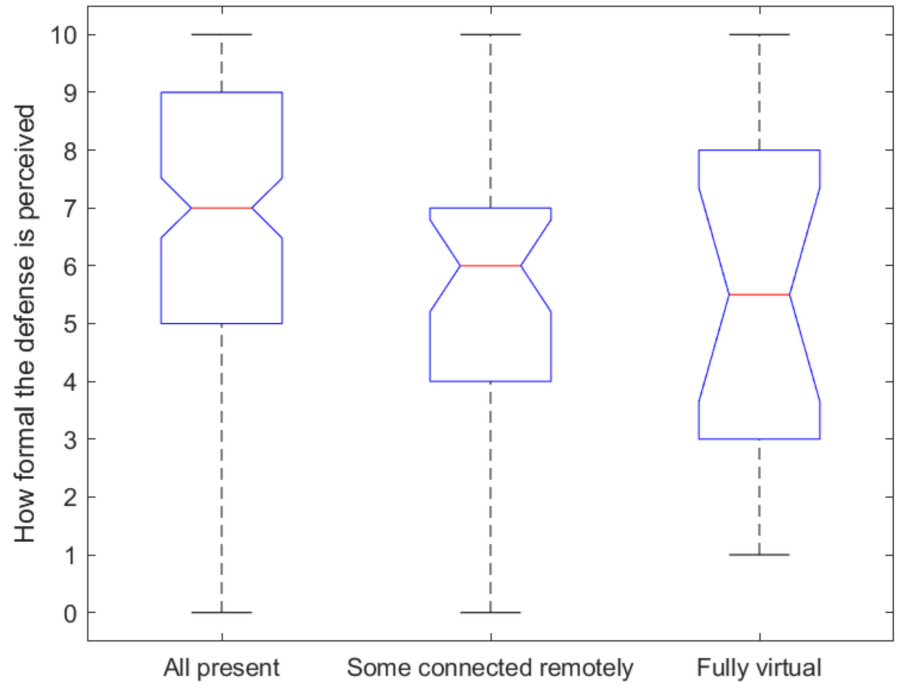

Figure 7. Perceived formality of defense as a function of in-person or (fully) remote committee.

A more formal dress code seems to positively impact the student's perception. Both the student's enjoyment $(p=0.0018)$ and the overall perceived value (Figure $8, p=0.0008$ ) of the defense correlated with the dress code of the defense. After organizing the data into groups with a dress code and without a dress code, I found that the average perceived value for the defenses with a dress code (avg $=8.2985)$ was higher than for those without (avg = 7.0379), $p=3.7 \times 10^{-4}$; and that the average enjoyment $(\mathrm{avg}=7.4615)$ was higher for those with than for those without (avg $=6.2061)$ a dress code, $p=0.0018$. Using a more formal dress code could be seen as a way to clearly mark the defense event, and may make the experience more memorable for the student.

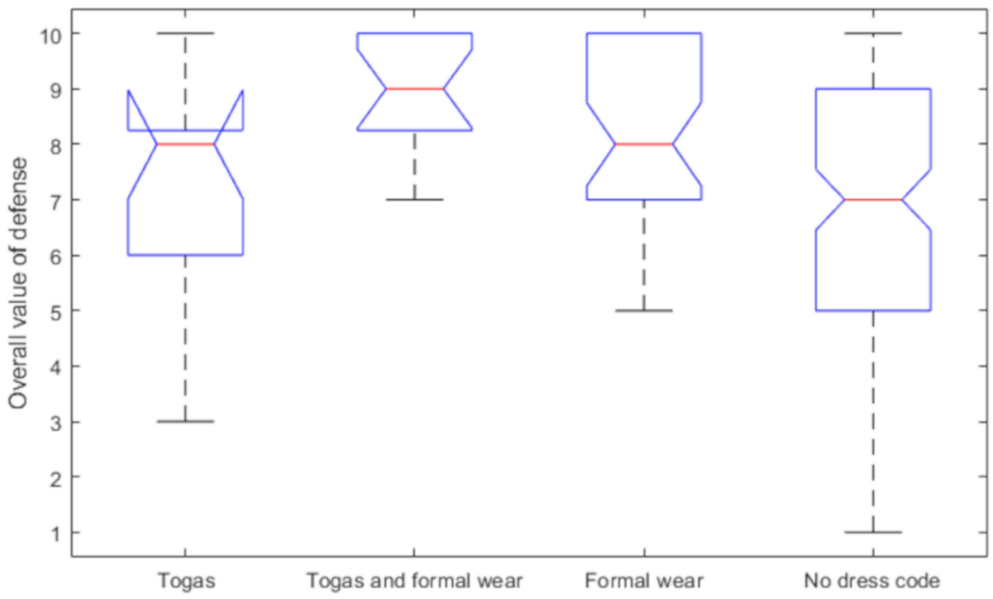

Figure 8. Overall value of the defense as a function of the dress code.

When the defense contained elements other than only the research, students tended to rate the overall value of the defense higher $(\mathrm{avg}=8.222)$ than when the defense was based on the research only (avg = 7.345), $p=0.0548$ with a Wilcoxon rank sum test, but $h=0$, indicating that the null hypothesis cannot be rejected. Other aspects of the emotional dimensions of the students' perceptions showed no correlations with whether the defenses contained other elements or not. In terms of the function of the defense, I observed that a defense that contains other elements is perceived more as a celebration $(55.6 \%)$ than a defense that does not $(30.9 \%)$. A potential explanation is that students for whom the defense format includes other elements can showcase their knowledge over a broader range of topics or skills, and enjoy this opportunity. However, only $13 \%$ of the respondents 
had a defense format that included other elements than only the research in the thesis, and these additional elements varied widely. Further research is necessary to study the different additional elements that can make up the defense, and how each of these elements, separately, is rated and perceived by the students.

Generally, a laudatio has a positive impact on the student's perception of the defense. Students whose defense formats contained a laudatio enjoyed their defenses more (average $=7.405)$ than those whose formats did not (average $=6.061)(p=0.0003)$; see Figure 9a. There was no relation between defense formats with or without a laudatio and nervousness before and during the defense. However, those who had defense formats that included a laudatio were less nervous after their defenses (average $=3.421)$ while waiting for their outcomes than those who did not have a laudatio (average $=4.455)(p=0.0121)$; see Figure $9 \mathrm{~b}$. A defense with a laudatio is perceived as more formal (average $=7.60$ ) than a defense without (average $=5.513)\left(p=7.49 \times 10^{-9}\right)$; see Figure 9c. A defense with a laudatio is also perceived as more difficult $(\operatorname{avg}=6.318)$ than a defense without (avg = 5.586) ( $p=0.0111$ ); see Figure 9d. In terms of perception of the function of a defense, the results show that a defense with a laudatio is perceived as less $(72.09 \%)$ like an exam than a defense without a laudatio $(82.76 \%)$, more of a ceremony $(63.95 \%$ for a defense with a laudatio and $25.86 \%$ for a defense without), and more of a celebration $(47.67 \%$ for a defense with a laudatio and $24.14 \%$ for a defense without). Finally, in terms of overall value of the defense, the perceived value of a defense with a laudatio is higher $(\mathrm{avg}=8.168)$ than a defense without $(\operatorname{avg}=6.922)(p=0.0002)$; see Figure 9e.

A laudatio marks the formal appreciation of the supervisor for the newly graduated doctor, and as such makes the defense a more memorable event, which is more positively evaluated by students than defenses without a laudatio.

There is a limited influence of language nativeness on student perception. Language nativeness does not influence nervousness, enjoyment, perceived importance, or overall value of the defense, but it does influence the perceived formality of the defense $(p=0.0076)$; see Figure 10. Non-native speakers got the largest boost in their perception of academic competence. A large majority $(70.1 \%)$ of those who defended as non-native speakers and $76.2 \%$ of the near-natives to the language of the defense reported that the defense increased their perceptions of their own academic competence. These values are in contrast to $47.6 \%$ of the native speakers reporting perceived increases in their academic competence. These results may be explained by the hypothesis that in hindsight, non-native speakers feel prouder of obtaining their doctorates in foreign languages than those who acquired their doctorates in their native languages. The non-native speakers have to master both a research topic and master another language to a high level. However, how being a native language speaker impacts students' perceptions and perceived competence is a large and complex topic [20] that is outside the scope of the current study.

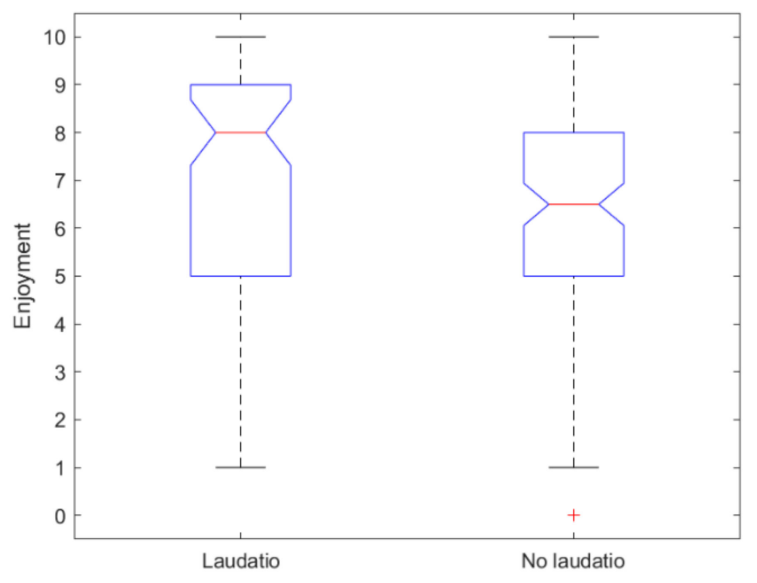

(a)

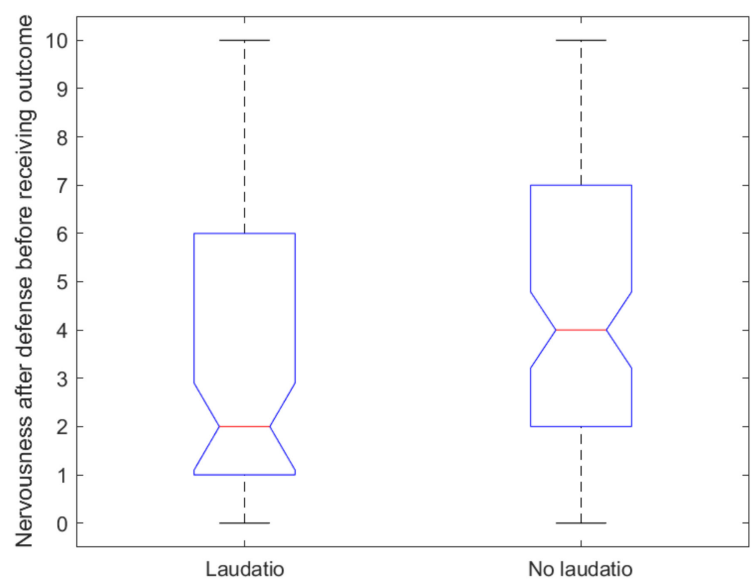

(b)

Figure 9. Cont. 


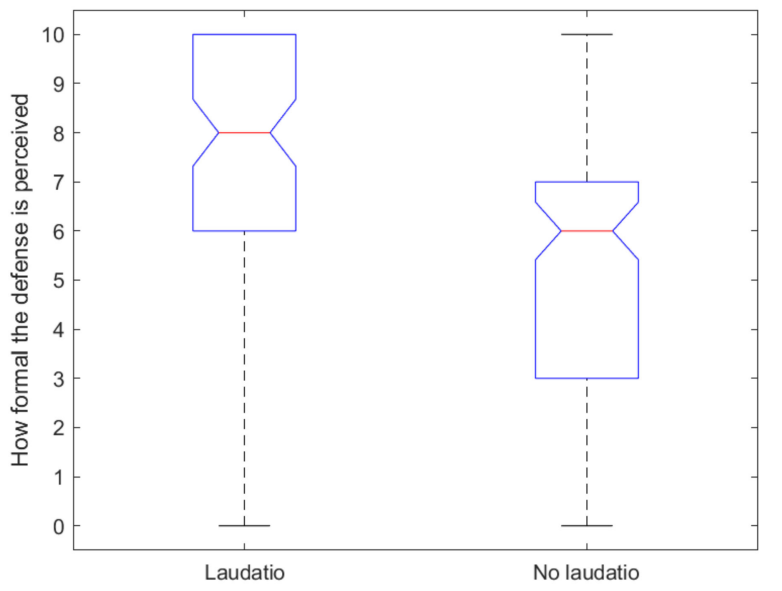

(c)

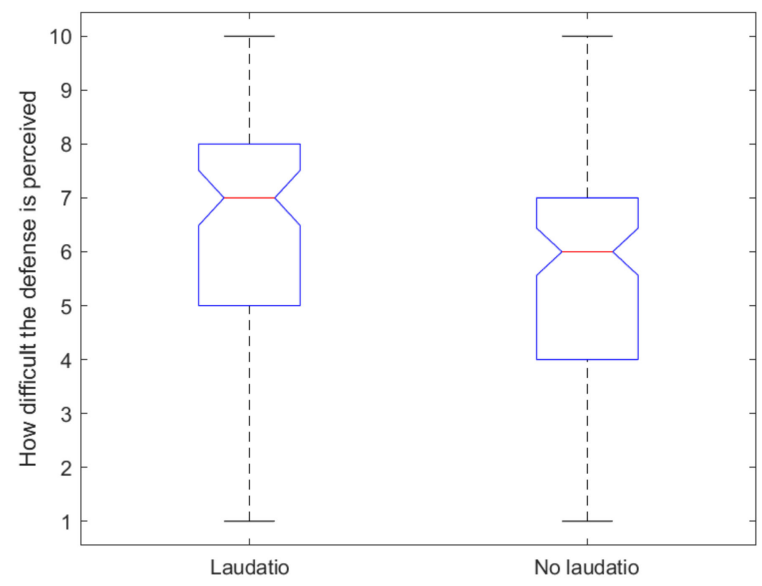

(d)

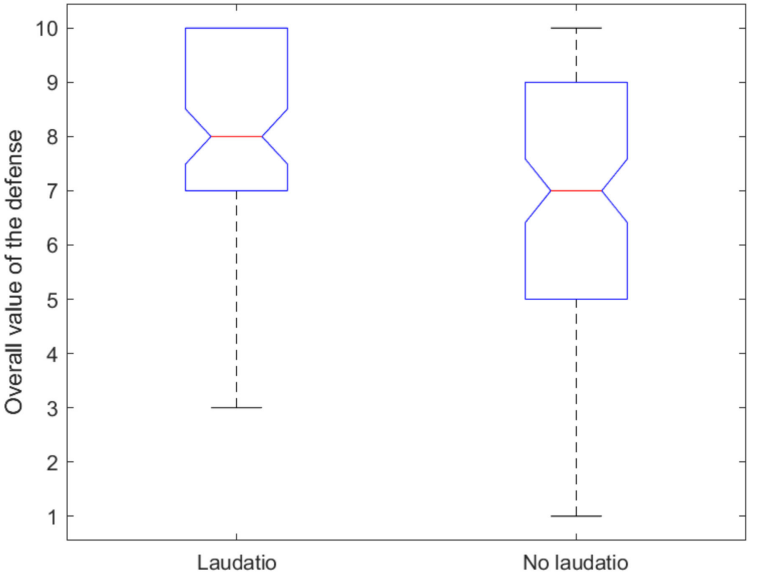

(e)

Figure 9. Relations between student perception and laudatio: (a) enjoyment, (b) nervousness after defense and before receiving outcome, (c) formality, (d) difficulty, (e) overall value of defense experience.

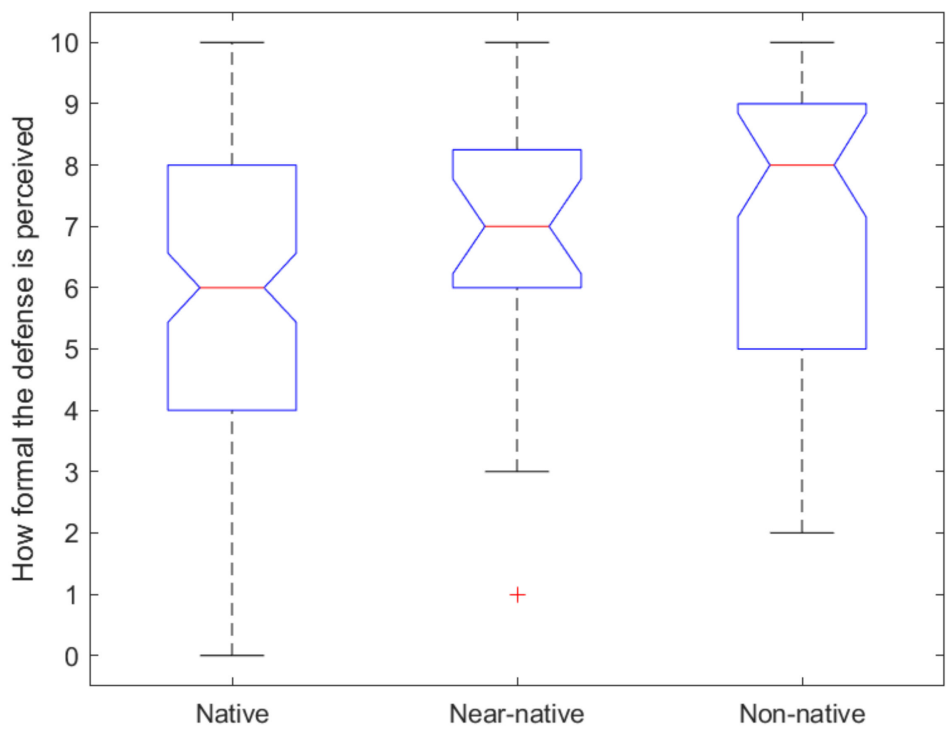

Figure 10. Perceived formality of defense as a function of language nativeness.

\section{Discussion}

Since this work represents the first study that has attempted to link elements of the defense format to students' perceptions of the defense, a direct comparison with previous 
work is not possible. However, several aspects of this work allow for comparisons to findings from the literature.

The first aspects to discuss are the influences of the major elements of the defense format on students' perceptions. Those major elements of the defense formats are those elements that I identified in previous work [22] as those elements that have the largest impacts on how the defense is carried out, and on the function of the defense in a student's trajectory towards obtaining the doctorate and graduating from the PhD program. From these five major elements, I found that the only element that had an influence on students' perceptions is whether the thesis is published before the defense or after the defense. I did not have sufficient data to make conclusions about the difference between a written and oral defense format.

Defending the thesis in one or two steps does not have a significant impact on the student's perceptions. Similarly, I found from the data that the influence of having a public or private defense on student perception is limited. It has been suggested that private defenses more often lead to abuses by committee members [10], as the committee members may feel less scruples about their misbehavior behind closed doors. However, I did not find evidence for this suggestion in this set of data. The results seem to indicate that what matters is how the committee members behave during the defense, regardless of them being in closed quarters or not. The fifth and final main difference in defense formats is whether the defense format follows a fixed-time schedule or can be driven by the committee. I replaced this element with the duration of the defense, as answers in the "other, please explain" textbox indicated that this question allowed for multiple interpretations. The impacts of the duration of the defense on the student's perceptions were, again, limited. Students do not seem to perceive defenses that take more time as more difficult defenses.

The second main topic to discuss here is the overall influences of the minor elements of the defense format on student perceptions. These minor elements of the defense formats are elements that I identified in previous work [22] as differences that have only limited impacts on the overall timeline of the defense. Some of these could be considered just cosmetic differences in the look and feel of the defense. The first element is related to the level of input a student has from the committee on the thesis before the defense. Receiving committee feedback before the defense improves the student's perceptions. Similarly, knowing the recommendations before the defense improves the student's perceptions, as these two dimensions take away uncertainties about the defense and the opinions of the committee. In the open-ended questions, respondents indicated in a few cases misbehavior of committee members. These difficulties have been addressed previously in the literature as well [9]. Moreover, one respondent also reported a male committee member displaying negative behavior against feminist scholarship, which has also been reported in the literature previously $[10,12]$. Misbehavior and unprofessionalism on the side of the committee members is not something that can be avoided by having a certain defense format, but requires careful selection of committee members within collegial networks.

Committee composition has no impact on students' perceptions, except that having a committee member internal to the department resulted in a slightly lower overall value. Student perceptions were not correlated with who asked the questions during the defense: all the committee members, some committee members, or any combination in which the audience was also allowed to ask questions resulted in similar perceptions.

A second less important element of the doctoral defense format is the presence or lack thereof of the supervisor. Having a supervisor present during the defense (as a committee member or as a member of the audience) has a positive impact on the perception of the student. This observation is in line with what Watts [2] called the psychological and practical elements of support the presence of the supervisor can bring. This observation is also in line with what Jacobs [35] mentioned: "Knowing that you've got at least one person in the room who truly does 'have your back' is huge." I, however, assume here that this statement may only be true when the relation between the candidate and supervisor is based on support, trust, and mutual respect. A third minor element of the doctoral defense is whether the 
defense includes a presentation or not. Having a presentation as part of the defense format seems to have a positive impact on the student's perceptions, but significant correlations could not be found. My hypothesis here is that students feel less like they are "preparing in the dark" [2] when they are preparing the actual presentation that they will give, and when the questions will potentially be centered around the information in the presentation. However, statistical support is lacking at the moment, and a possible explanation for this lack of statistical proof may be that a presentation can be used in various ways, which each have various impacts on the student. A presentation at the beginning of the defense for friends and family may be perceived differently from a presentation which forms the core of the discussions. A fourth minor element is how the committee members participated in the defense: virtually or in person. Overall, there seems to have been no correlation between virtual or in-person defense and student perceptions.

A fifth minor element is related to the dress code during the defense. A more formal dress code seems to positively impact the students' perceptions. While such an element may be dismissed as only a cosmetic difference, the use of a more formal dress code does seem to correlate with more a positive perception by the student. Similarly, including a laudatio at the end of the defense has a positive impact on the perceptions of students. These festive elements seem to help make the defense a more memorable and positive experience for the student. A seventh and final minor element is whether the defense focused on the research only, or included other elements. When the defense contained elements other than the research, students tended to rate the overall value of the defense higher. However, since the types of additional aspects that can be included in a defense vary, further research is necessary to correlate these different elements with the students' perceptions.

One overall finding is that the data of this study show that students found the defense a positive experience. This study highlights that the defense should not be abolished, but that we should seek to improve it. We can frame these discussions in the light of internationalization and the need for best practices. The observation that the defense is a valuable experience answers a question about the value of the defense asked by Wellington [3].

In terms of research on perceptions of supervisors related to the defense format, Goulding and Geraghty [44] carried out a survey regarding the implementation of European standards in UK doctoral education in the field of pharmacology. The responses, along with interviews with supervisors and sentiments expressed during a workshop on this topic, overwhelmingly showed that UK supervisors are convinced that the UK viva in its format is to be preferred over the continental defense, which includes iterations towards the final dissertation and defense by processing committee feedback. This perception of supervisors is in contrast to research outcomes from the literature, which show the particularities and drawbacks of the closed British defense $[5,7,17]$. In this study, however, the only element of difference between the continental and British defense formats that was found to have an impact on students' perceptions was whether the thesis was published before or after the defense.

From the qualitative analysis of the open-ended questions, I also conclude that a student's perception of their defense is a very personal experience. As identified in the literature $[10,17,45]$, the affective aspect of the doctoral defense, and the doctoral journey at large, is as important as the scholarly and cultural aspects. Yet, most of our attention focuses on the scholarly aspect, while the affective and cultural aspects are often neglected. One of the insights of Sikes [9] draws on the commentary of Davies [46] that neoliberal governments want to consider everyone as having measurable and manipulative characteristics, so that any student can be considered as an object that can be categorized and made predictable. In the light of doctoral assessment, such characteristics, categorization, and predictability do not reflect the messiness, subjectivity, and emotional dimensions involved with the doctoral defense. As such, it is necessary to acknowledge this, and share experiences. By focusing on the experiences of students in this work, I hope to start the discussion on how the affective aspect plays a role. 
The limitations of this study are related to the self-selecting sample of respondents. Most of the respondents were recruited through Twitter and LinkedIn, and by email. While over 30 countries were represented in the survey, the regions that were most represented in the survey are also the regions where I personally know more people and/or where I have worked, lived, and studied myself. A second limitation of the current study is that the data came only from students recalling and describing their experiences in hindsight, rather than from direct observations or written reports. This issue is often faced when researching doctoral education [10]. A third limitation is that minorities were not well-represented among the respondents.

Based on this study, I have identified potential topics of further research. The first topic that requires further research is related to the inclusion or not of a presentation, and other elements, during the defense. To clarify these aspects, further research on the function of the presentation during the defense, and how a presentation potentially steers discussion during a defense, is necessary. Similar questions remain to be answered about the other elements that can be included in a defense format. Moreover, more research on committee composition is necessary. In particular, more defenses in which members from industry and/or the government participate should be studied, and correlated with student perceptions.

Other topics that require further research are: exploring how minorities experience the doctoral defense, widening the geographical breadth of the analysis of defense formats, in-depth interviews with recently graduated doctoral candidates, a study on the impacts of committee members and supervisors on students' perceptions, a study on the influence of how students prepare for the defense on the defense experience and outcome, and a further study on how socio-demographic factors impact students' perceptions.

\section{Conclusions}

In this article, I analyzed a survey that I carried out on doctoral defense formats and the perceptions of students. From the data, I studied those elements separately, and also studied which elements of the doctoral defense format and students' perceptions are correlated. The following elements were found to positively impact the students' perceptions of the doctoral defense:

- Publication of the thesis before the defense.

- Receiving committee feedback before the defense.

- Knowing the recommendations of one or more member of the committee before the defense.

- Having the supervisor present in the defense as a committee member or in the audience.

- Using a formal dress code and/or academic togas during the defense.

- Including a laudatio at the end of the defense.

Two elements were found the positively impact the students' perceptions of the doctoral defense, but require further study, as no statistical significance could be found. These elements are including a presentation in the defense format, and including other elements outside of the thesis research in the defense format.

Of the five major differences in defense formats, only the element of publishing the thesis before or after the defense was found to have an impact on the students' perceptions of the defense. Conversely, of the seven minor differences in defense formats, six elements impacted the students' perceptions of their defenses. While these minor differences do not impact the overall timeline of a student's trajectory towards obtaining the doctorate, they change the look and feel of the defense. Since the emotional aspects of the doctoral defense are important, it is actually the details that can improve how a student feels during the defense, and how he/she reflect back on the defense afterwards.

A second major finding of this work is that the doctoral defense is, on average, considered to be a valuable experience. As such, the data indicate that we should not seek to abolish the doctoral defense, but to improve it. 
While we should strive to come to a defense format that can be considered a positive experience for every student, one of the conclusions of this work is that two elements that are outside the reach of the defense format have large influences on the students' perceptions of the defense. The first element includes the personal experience and feelings of the student before, during, and after the defense. Since a personal experience is vastly subjective, it is difficult to "control" the experience through a defense format. Supervisors and committee members should be aware of and sensitive to the emotional aspects of the defense for the student. The second element that has a large impact, and that was observed clearly from the qualitative analysis of the open-ended questions, is the behavior of committee members during the defense. Regardless of the defense format, a committee member can focus all his/her effort on questions that are only tangentially related to the thesis, or behave poorly (by, for example, arriving late). Here, the development of guidelines and best practices for committee members could be a solution, involving training of supervisors and committee members on how to positively participate in doctoral defenses.

Supplementary Materials: The following are available online at https:/ / www.mdpi.com/article/10 $.3390 /$ educsci11090519/s1.

Funding: This research received no external funding.

Institutional Review Board Statement: Ethical review and approval were waived for this study, due to study with data collection with anonymized participants and adult population. Case 2019-139IN Universidad San Francisco de Quito.

Informed Consent Statement: Informed consent was obtained from all subjects involved in the study.

Data Availability Statement: The dataset generated by this research is available in the public domain: https:/ / doi.org/10.5281/zenodo.5045412.

Acknowledgments: I'd like to thank the participants who responded to my questionnaire about doctoral defense formats.

Conflicts of Interest: The author declares no conflict of interest.

\section{References}

1. Barnett, J.V.; Harris, R.A.; Mulvany, M.J. A comparison of best practices for doctoral training in Europe and North America. FEBS Open Bio 2017, 7, 1444-1452. [CrossRef]

2. Watts, J.H. Preparing doctoral candidates for the viva: Issues for students and supervisors. J. Furth. High. Educ. 2012, 36, 371-381. [CrossRef]

3. Wellington, J. Supporting students' preparation for the viva: Their pre-conceptions and implications for practice. Teach. High. Educ. 2010, 15, 71-84. [CrossRef]

4. Mežek, Š.; Swales, J.M. PhD defences and vivas. In The Routledge Handbook of English for Academic Purposes; Hyland, K., Shaw, P., Eds.; Routledge: London, UK, 2016; pp. 361-375.

5. Tinkler, P.; Jackson, C. Examining the doctorate: Institutional policy and the phd examination process in britain. Stud. High. Educ. 2000, 25, 167-180. [CrossRef]

6. Clarke, G.; Lunt, I. The concept of 'originality' in the Ph.D.: How is it interpreted by examiners? Assess. Eval. High. Educ. 2014, 39, 803-820. [CrossRef]

7. Jackson, C.; Tinkler, P. Back to basics: A consideration of the purposes of the PhD viva. Assess. Eval. High. Educ. 2001, 26, 355-366. [CrossRef]

8. Driggers, R. Norwegian doctoral defense: Editorial. Appl. Opt. 2015, 54, ED7-ED8. [CrossRef] [PubMed]

9. Sikes, P. And then he threatened to kill himself: Nightmare viva stories as opportunities for learning. Qual. Res. J. 2017, 17, 230-242. [CrossRef]

10. Morley, L.; Leonard, D.; David, M. Quality and equality in british PhD assessment. Qual. Assur. Educ. 2003, 11, 64-72. [CrossRef]

11. Remenyi, D.; Money, A.; Price, D.; Bannister, F. The doctoral viva: A great educational experience of a gun fight at the ok corral? Ir. J. Manag. 2003, 24, 105-116.

12. Morley, L.; Leonard, D.; David, M. Variations in vivas: Quality and equality in british phd assessments. Stud. High. Educ. 2002, 27, 263-273. [CrossRef]

13. Remenyi, D. Never smile at a crocodile: A bad viva voce by the rule book. Electron. J. Bus. Res. Methods 2019, 17, 67-73. [CrossRef]

14. Kyvik, S. Assessment procedures of norwegian PhD theses as viewed by examiners from the USA, the UK and Sweden. Assess. Eval. High. Educ. 2014, 39, 140-153. [CrossRef]

15. Hartley, J.; Jory, S. Lifting the Veil on the Viva: The Voice of Experience; BERA Seminar: London, UK, 2000. 
16. Share, M. The PhD viva: A space for academic development. Int. J. Acad. Dev. 2016, 21, 178-193. [CrossRef]

17. Crossouard, B. The doctoral viva voce as a cultural practice: The gendered production of academic subjects. Gend. Educ. 2011, 23, 313-329. [CrossRef]

18. Davis, G.; Engward, H. In defence of the viva voce: Eighteen candidates' voices. Nurse Educ. Today 2018, 65, 30-35. [CrossRef] [PubMed]

19. Eggleston, J.F.; Delamont, S.; British Educational Research Association. Supervision of Students for Research Degrees: With Special Reference to Educational Studies; British Educational Research Association: London, UK, 1983.

20. Carter, S. English as an additional language (eal) viva voce: The eal doctoral oral examination experience. Assess. Eval. High. Educ. 2012, 37, 273-284. [CrossRef]

21. Fariñas, L. PhD Defenses around the World: A Defense in Spain PhD Talk. 2017. Available online: https://www.evalantsoght. com/2017/01/phd-defenses-around-the-world-a-defense-in-spain.html (accessed on 30 June 2021).

22. Degtyareva, O.; Lantsoght, E.O.L. Planning and Passing Your Phd Defence-A Global Toolbox for Success; Routledge: Abingdon, UK, 2021.

23. Coupland, K. PhD Defenses around the World: A Defense in Neuroscience from Australia PhD Talk. 2018. Available online: https: //www.evalantsoght.com/2018/02/phd-defenses-around-the-world-a-defense-in-neuroscience-from-australia.html (accessed on 30 June 2021).

24. Hansen, J.A.; Lehmann, M. Agents of change: Universities as development hubs. J. Clean. Prod. 2006, 14, 820-829. [CrossRef]

25. Golding, C.; Sharmini, S.; Lazarovitch, A. What examiners do: What thesis students should know. Assess. Eval. High. Educ. 2014, 39, 563-576. [CrossRef]

26. Johnston, S. Examining the examiners: An analysis of examiners' reports on doctoral theses. Stud. High. Educ. 1997, 22, 333-347. [CrossRef]

27. Lantsoght, E. A PhD Defense at Georgia Tech. PhD Talk. 2011. Available online: https://www.evalantsoght.com/2011/08/aphd-defense-at-georgia-tech.html (accessed on 30 June 2021).

28. Masuzzo, P. PhD Defenses around the World: A Defense in Bioinformatics in Belgium PhD Talk. 2017. Available online: https: //www.evalantsoght.com/2017/06/phd-defenses-around-the-world-a-defense-in-bioinformatics-in-belgium.html (accessed on 30 June 2021).

29. Mallinson, D.J. PhD Defenses around the World: A Defense in Political Science from Penn State PhD Talk. 2016. Available online: https:/ / www.evalantsoght.com/2016/06/phd-defenses-around-the-world-a-defense-in-political-science-from-pennstate.html (accessed on 30 June 2021).

30. Muqoz Llancao, P. PhD Defenses around the World: Universidad de Chile and University of Groningen, The Netherlands. PhD Talk. 2016. Available online: https:/ / www.evalantsoght.com/2016/03/phd-defenses-around-the-world-universidad-de-chileand-university-of-groningen-the-netherlands.html (accessed on 30 June 2021).

31. Lantsoght, E. A PhD Defense at Tu Delft PhD Talk. 2011. Available online: https://www.evalantsoght.com/2011/01/a-phddefense-at-tu-delft.html (accessed on 30 June 2021).

32. Shields, P. PhD Defenses around the World: A Defense from the University of Charleston. PhD Talk. 2018. Available online: https: //www.evalantsoght.com/2018/08/phd-defenses-around-the-world-a-defense-from-the-university-of-charleston.html (accessed on 30 June 2021).

33. Lantsoght, E. PhD Talk for Academictransfer: Defending Your PhD in The Netherlands. PhD Talk. 2020. Available online: https: //www.evalantsoght.com/2020/11/phd-talk-for-academictransfer-defending-your-phd-in-the-netherlands.html (accessed on 30 June 2021).

34. Leung, S.O. A comparison of psychometric properties and normality in 4-, 5-, 6-, and 11-point likert scales. J. Soc. Serv. Res. 2011, 37, 412-421. [CrossRef]

35. Jacobs, S. PhD Defenses around the World: I Passed and You Will Too PhD Talk. 2018. Available online: https://www. evalantsoght.com/2018/12/phd-defenses-around-the-world-i-passed-and-you-will-too.html (accessed on 30 June 2021).

36. Huppatz, K.; Sang, K.; Napier, J. 'If you put pressure on yourself to produce then that's your responsibility': Mothers' experiences of maternity leave and flexible work in the neoliberal university. Gend. Work Organ. 2019, 26, 772-788. [CrossRef]

37. Ryder, N. Viva Experience Research, Part 2: Some Statistics. 2014. Available online: https://www.nathanryder.co.uk/2014/10/ viva-research-part-2/ (accessed on 30 June 2021).

38. NSF. Survey of Earned Doctorates; National Science Foundation: Washington, DC, USA, 2019.

39. Jamieson, S. Likert scales: How to (ab) use them. Med. Educ. 2004, 38, 1217-1218. [CrossRef] [PubMed]

40. Kilty, T.J.; Burrows, A.C. Secondary science preservice teachers' perceptions of engineering: A learner analysis. Educ. Sci. 2019, 9 , 29. [CrossRef]

41. Braun, V.; Clarke, V. Using thematic analysis in psychology. Qual. Res. Psychol. 2006, 3, 77-101. [CrossRef]

42. Lofland, J.; Snow, D.A.; Anderson, L.; Lofland, L.H. Analyzing Social Settings: A Guide to Qualitative Observation and Analysis; Wadsworth: Belmont, CA, USA, 2006.

43. Lantsoght, E.O.L. Dataset Doctoral Defenses and Defense Formats. Zenodo 2021. [CrossRef]

44. Goulding, N.J.; Geraghty, A. Standards for phd education in pharmacology in the uk. Turk. J. Biochem. 2011, 36, 19-25.

45. Burford, J. Not writing, and giving 'zero-f** ks' about it: Queer(y)ing doctoral 'failure'. Discourse Stud. Cult. Politics Educ. 2017, 38, 473-484. [CrossRef]

46. Davies, B. Listening to Children: Being and Becoming; Routledge: London, UK, 2014; p. 120. 